\title{
Full and Reduced-Order Unknown Input Observer Design for Linear Time-Delay Systems with Multiple Delays
}

\author{
Seifeddine Ben Warrad, ${ }^{1}$ Olfa Boubaker ${ }^{D},{ }^{1}$ Mihai Lungu $\left(\mathbb{D},{ }^{2}\right.$ and Saleh Mobayen ${ }^{3}$ \\ ${ }^{1}$ National Institute of Applied Sciences and Technology, Centre Urbain Nord, BP 676, 1080 Tunis Cedex, Tunisia \\ ${ }^{2}$ University of Craiova, Faculty of Electrical Engineering, 107 Decebal Blvd., Craiova, Romania \\ ${ }^{3}$ Advanced Control Systems Laboratory, Department of Electrical Engineering, University of Zanjan, University Blvd., \\ 45371-38791 Zanjan, Iran
}

Correspondence should be addressed to Olfa Boubaker; olfa.boubaker@insat.rnu.tn

Received 31 July 2018; Revised 2 November 2018; Accepted 11 November 2018; Published 26 November 2018

Academic Editor: Francesco Conte

Copyright (c) 2018 Seifeddine Ben Warrad et al. This is an open access article distributed under the Creative Commons Attribution License, which permits unrestricted use, distribution, and reproduction in any medium, provided the original work is properly cited.

In this work, we consider the design problem of a full-order and also reduced-order unknown input observers for a particular class of time-delay systems. Asymptotic stability and existence conditions for the designed observers are established. The quadruple-tank process is used as a benchmark to prove the efficiency of the proposed algorithms.

\section{Introduction}

Time delays emerge in many industrial applications such as hydraulic systems, automotive applications, and telecommunication networks [1-7]. Commonly, delays describe propagation phenomena, energy transfer, or data transmission. Furthermore, it is recognized that delays are the key sources of instability and poor dynamics [8]. Since the sixteen's century, the research theme of time-delay systems has concerned lots of interest and has been considered as one of the essential research areas in control theory for which many significant research works have been devoted. The topical survey [9] and the recent books [10-12] as well as their related references prove the richness and maturity of this field. Time delays can appear in either the state variables, control inputs, or measurement outputs and the negligence of time delays in the controller design can lead to undesirable dynamics such as oscillations, bifurcations, chaos dynamics, and instability [8]. In this trend, stabilization of linear systems with delays has obtained a huge interest (see, for example, recent works [13-15] and related references). As reported in [16], for stabilization of continuous linear systems subject to time delays, most research works only focus in systems with input delays and solve the problem in the absence of state delays. To the best of the authors' knowledge, few research works have considered the stabilization problem with multiple delays in states and inputs where the problem is generally solved by assuming fully available state variables [1] or by resorting to output-feedback controllers [17]. The design problem of observer-based stabilization for systems with multiple delays in states and inputs is rarely solved $[16,18]$. Until now, this issue of theoretical and practical importance has been remained a challenging problem for systems subject to unknown inputs, uncertainties, and input saturation.

In control theory, modeling and controlling benchmark systems is another fundamental issue. Such systems are considered as challenging control problems, yet, in spite of their uncomplicated arrangement. In this outline, several systems are commonly used in control theory for testing novel control algorithms. We can cite in this framework the three-tank process [19], mass-spring-damper system [20], bouncing ball [21], TORA system [22], hard-disk drive system [23], magnetic levitation system [24], cart-inverted pendulum [25], Furuta pendulum [26], reaction wheel pendulum [27], beam-and-ball [28], two-link flexible manipulator [29], and so on. In the same direction, the well-known quadrupletank benchmark [30-36] has attracted many attention since it can show elementary notions in estimation and control theory, particularly performance limitation due to the 
nonminimum-phase zeros and their output directions for multivariable systems. This system is composed of four coupled tanks, two pumps, and two valves [35]. Many research papers have been devoted to the problem of observer and controller design of this benchmark system without consideration of time delays [37-43] and to the best of our information, no researches have been investigated for unknown input observer design of time-delay quadruple-tank systems.

Motivated by the authors' early works for linear systems without delays [44], in this paper, we expand the problem of full-order unknown input observer (FOUIO) and reducedorder unknown input observer (ROUIO) design for linear systems with multiple time delays in states and inputs affected by unknown inputs. In this framework, it is important to note that a FOUIO is designed in [45-47] for linear systems with a single delay in the states and two delays in the inputs whereas another FOUIO is proposed in [48] for linear systems with a single delay in the states and a single delay in the inputs. For the last works, only the state information is used to design observers in open loops and to the best of our knowledge, there are no related works for which both the state vector and the input vectors are used to design the observer. Furthermore, in our best knowledge, there is not in the vast literature ROIU design approach that attempts to solve such a problem.

The design procedures of both reduced-order and fullorder observers are considered here. The key contributions of this work can be recapitulated as follows:

(i) The designed observers' approaches do not require approximation of the infinite dimensional model of the delayed system in a lumped one as described in our previous works $[45,46]$.

(ii) Different from [46] where only the state vector is used to construct observers in open loop, in this paper, we construct the novel observers by using both state and input vectors. The structure of the proposed observers allows us to introduce more observer gains that can accomplish better control performance.

(iii) Different from the observer designed in [47] where the delayed system introduces a single delay in the states and a single delay in the inputs, in this paper, multiple time delays in the inputs are considered.

The rest of this paper is organized as follows: the problem statement is considered in Section 2. The full-order observer is designed in Section 3 whereas the reduced-order observer is developed in Section 4. Section 5 is devoted to the application of the proposed approaches to the quadruple-tank benchmark. Finally, conclusions are provided in Section 6.

\section{Problem Statement}

Consider a class of time-delay systems described by

$$
\begin{aligned}
\dot{\mathrm{x}}(\mathrm{t})= & \mathrm{A}_{0} \mathrm{x}(\mathrm{t})+\mathrm{A}_{1} \mathrm{x}\left(\mathrm{t}-\tau_{0}\right)+\sum_{\mathrm{i}=0}^{\mathrm{k}}\left(\mathrm{B}_{\mathrm{i}} \mathrm{u}\left(\mathrm{t}-\tau_{\mathrm{i}+1}\right)\right) \\
& +\mathrm{Dd}(\mathrm{t}) \\
\mathrm{y}(\mathrm{t})= & \mathrm{Cx}(\mathrm{t})
\end{aligned}
$$

where $\mathrm{x}(\mathrm{t}) \in \mathscr{R}^{\mathrm{n}}$ is the state vector, $\mathrm{u}(\mathrm{t}) \in \mathscr{R}^{\mathrm{m}}$ is the input vector, $\mathrm{d}(\mathrm{t}) \in \mathscr{R}^{\mathrm{q}}$ is the unknown input vector, and $\mathrm{y}(\mathrm{t}) \in \mathscr{R}^{\mathrm{p}}$ is the output vector; $\mathrm{A}_{0} \in \mathscr{R}^{\mathrm{n} \times \mathrm{n}}, \mathrm{A}_{1} \in \mathscr{R}^{\mathrm{n} \times \mathrm{n}}$, $\mathrm{B}_{\mathrm{i}} \in \mathscr{R}^{\mathrm{n} \times \mathrm{m}}, \mathrm{C} \in \mathscr{R}^{\mathrm{p} \times \mathrm{n}}$, and $\mathrm{D} \in \mathscr{R}^{\mathrm{n} \times \mathrm{q}}$ are constant matrices with appropriate dimensions, while $\tau_{0}$ and $\tau_{\mathrm{i}+1}$ for $\mathrm{i}=0, \ldots, \mathrm{k}$ are known and constant time delays.

The objective of this paper is to design two different approaches of unknown input observers (UIOs) for system (1):

(1) An FOUIO is described by

$$
\begin{aligned}
& \dot{\zeta}(\mathrm{t})=\mathrm{N} \zeta(\mathrm{t})+\mathrm{Ly}(\mathrm{t})+\mathrm{Jy}\left(\mathrm{t}-\tau_{0}\right)+\sum_{\mathrm{i}=0}^{\mathrm{k}} \mathrm{G}_{\mathrm{i}} \mathrm{u}\left(\mathrm{t}-\tau_{\mathrm{i}+1}\right), \\
& \widehat{\mathrm{x}}(\mathrm{t})=\zeta(\mathrm{t})-\operatorname{Ey}(\mathrm{t}),
\end{aligned}
$$

where $\zeta(\mathrm{t}) \in \mathscr{R}^{n}$ and $\widehat{\mathrm{x}}(\mathrm{t}) \in \mathscr{R}^{\mathrm{n}}$ are the observer state vector and the estimated state vector, respectively. N, L, J, E, and $\mathrm{G}_{\mathrm{i}}(\mathrm{i}=0 . \ldots \mathrm{k})$ are matrices of appropriate dimensions to be calculated such that $\widehat{x}(\mathrm{t})$ converges asymptotically to $\mathrm{x}(\mathrm{t})$ under the following assumptions: $(\mathrm{A} 1) \operatorname{rank}(\mathrm{D})=\mathrm{q} ;(\mathrm{A} 2)$ $\operatorname{rank}(\mathrm{C})=\mathrm{p} ;(\mathrm{A} 3)$ the pair $\left(\mathrm{A}_{0}, \mathrm{C}\right)$ is observable (detectable).

(2) An ROUIO is also designed in this paper for the estimation of the state vector $\mathrm{x}(\mathrm{t})$ by obtaining the estimation of the vector: $\bar{\zeta}(\mathrm{t})=\mathrm{Fx}(\mathrm{t}), \mathrm{F} \in \mathscr{R}^{\mathrm{s} \times \mathrm{n}}$, where $\bar{\zeta}(\mathrm{t}) \in \mathscr{R}^{\mathrm{s}}$ is the vector enclosing a part of the system's states or a combination of them. The dynamics of the ROUIO is

$$
\begin{aligned}
\mathrm{z} \dot{\bar{\zeta}}(\mathrm{t})= & \overline{\mathrm{N}} \widehat{\bar{\zeta}}(\mathrm{t})+\overline{\mathrm{L}} \mathrm{y}(\mathrm{t})+\overline{\mathrm{J}} \mathrm{y}\left(\mathrm{t}-\tau_{0}\right) \\
& +\sum_{\mathrm{i}=0}^{\mathrm{k}} \overline{\mathrm{G}}_{\mathrm{i}} \mathrm{u}\left(\mathrm{t}-\tau_{\mathrm{i}+1}\right) \\
\widehat{\mathrm{x}}(\mathrm{t})= & \mathrm{H} \hat{\bar{\zeta}}(\mathrm{t})+\overline{\mathrm{E}} \mathrm{y}(\mathrm{t})
\end{aligned}
$$

where $\widehat{\bar{\zeta}}(\mathrm{t}) \in \mathscr{R}^{\mathrm{s}}$ and $\widehat{\mathrm{x}}(\mathrm{t}) \in \mathscr{R}^{\mathrm{n}}$ are the observer state vector and estimated state vector, respectively. $\overline{\mathrm{N}} \in \mathscr{R}^{\mathrm{s} \times \mathrm{s}}, \overline{\mathrm{L}} \in \mathscr{R}^{\mathrm{s} \times \mathrm{p}}$, $\overline{\mathrm{J}} \in \mathscr{R}^{\mathrm{s} \times \mathrm{p}}, \overline{\mathrm{G}}_{\mathrm{i}} \in \mathscr{R}^{\mathrm{s} \times \mathrm{m}}$ for (i $\left.=0 . . \mathrm{k}\right), \mathrm{H} \in \mathscr{R}^{\mathrm{n} \times \mathrm{s}}, \overline{\mathrm{E}} \in \mathscr{R}^{\mathrm{n} \times \mathrm{p}}, \mathrm{F} \in$ $\mathscr{R}^{\mathrm{s} \times \mathrm{n}}$ and $\mathrm{Z} \in \mathscr{R}^{\mathrm{s} \times \mathrm{s}}$ are matrices of appropriate dimensions to be calculated such that $\widehat{\bar{\zeta}}(\mathrm{t})$ and $\widehat{\mathrm{x}}(\mathrm{t})$ converge asymptotically to $\bar{\zeta}(\mathrm{t})$ and $\mathrm{x}(\mathrm{t})$, respectively, under the assumptions as

(A4) $\operatorname{rank}(\mathrm{D})=\mathrm{q}$; (A5) $\operatorname{rank}(\mathrm{C})=\mathrm{p}$; (A6) the pair $\left(\mathrm{A}_{0}\right.$, C) is observable; (A7) $n>s>p \geq q$; (A8) $n=p+q$.

Remark 1. For the design procedure of ROUIO, a particular form for the matrix $\mathrm{C}$ can be chosen as $\mathrm{C}=\left[\begin{array}{ll}\mathrm{C}_{1} & 0_{\mathrm{p} \times \mathrm{q}}\end{array}\right]$, where $\mathrm{C}_{1} \in \mathscr{R}^{\mathrm{p} \times \mathrm{p}}$ is a full rank (nonsingular) matrix. This is not restrictive as long as the matrix $\mathrm{C}$ is full row rank (conditions $\mathrm{A} 2 \equiv \mathrm{A} 5$ ), and there will always be an orthogonal transformation which leads to the equation $\mathrm{y}(\mathrm{t})=\left[\begin{array}{ll}\mathrm{C}_{1} & 0\end{array}\right] \mathrm{x}(\mathrm{t})$.

Either for the FOUIO (2) or the ROUIO (3), system (1) is controlled using the state-feedback controller as

$$
\mathrm{u}=\mathrm{K} \widehat{\mathrm{x}}(\mathrm{t})
$$

where $\mathrm{K} \in \mathscr{R}^{\mathrm{m} \times \mathrm{n}}$ is designed using one of the appropriate approaches for system (1), for example, the approach proposed in [1]. 


\section{Design of the Full-Order Observer}

Theorem 2. Consider system (1) with assumptions (A1-A3) presented above. The FOUIO (2) is convergent, i.e., $\mathrm{e}(\mathrm{t}) \longrightarrow 0$ as $\mathrm{t} \longrightarrow \infty$ with an arbitrary convergence rate for any $x(0)$, $d(t)$, and $u(t)$, if there exists a positive-definite matrix $\mathrm{R} \in$ $\mathscr{R}^{\mathrm{n} \times \mathrm{n}}$ verifying the matrix inequality

$$
\mathrm{N}^{\mathrm{T}} \mathrm{R}+\mathrm{RN}<0
$$

and if the matrix $\mathrm{P}=(\mathrm{I}+\mathrm{EC}) \in \mathscr{R}^{\mathrm{n} \times \mathrm{n}}$ fulfills the following conditions:

$$
\begin{aligned}
\mathrm{NP}+\mathrm{LC}-\mathrm{PA}_{0} & =0, \\
\mathrm{JC}-\mathrm{PA}_{1} & =0 \\
\mathrm{G}_{\mathrm{i}}-\mathrm{PB}_{\mathrm{i}} & =0 \quad \forall \mathrm{i}=0 \cdots \mathrm{k}, \\
\mathrm{PD} & =0 .
\end{aligned}
$$

Proof. Define the observer reconstruction error vector as the difference between the estimated state $\widehat{\mathrm{x}}(\mathrm{t})$ described by (2) and the state vector related to system (1) as

$$
\begin{aligned}
e(t) & =\widehat{x}(t)-x(t)=\zeta(t)-x(t)-E y(t) \\
& =\zeta(t)-(I+E C) x(t) .
\end{aligned}
$$

Using (1) and (2), the dynamics of the estimation error becomes

$$
\dot{e}(t)=\dot{\zeta}(t)-(I+E C) \dot{x}(t)
$$

or

$$
\begin{aligned}
\dot{\mathrm{e}}(\mathrm{t})= & \mathrm{Ne}(\mathrm{t})+\left[\mathrm{N}(\mathrm{I}+\mathrm{EC})+\mathrm{LC}-(\mathrm{I}+\mathrm{EC}) \mathrm{A}_{0}\right] \mathrm{x}(\mathrm{t}) \\
& +\left[\mathrm{JC}-(\mathrm{I}+\mathrm{EC}) \mathrm{A}_{1}\right] \mathrm{x}\left(\mathrm{t}-\tau_{0}\right) \\
& +\sum_{\mathrm{i}=0}^{\mathrm{k}}\left(\left[\mathrm{G}_{\mathrm{i}}-(\mathrm{I}+\mathrm{EC}) \mathrm{B}_{\mathrm{i}}\right] \mathrm{u}\left(\mathrm{t}-\tau_{\mathrm{i}+1}\right)\right) \\
& -(\mathrm{I}+\mathrm{EC}) \mathrm{Dd}(\mathrm{t}) .
\end{aligned}
$$

Using P = I + EC, the error dynamics (9) is written in the following form:

$$
\begin{aligned}
\dot{\mathrm{e}}(\mathrm{t})= & \mathrm{Ne}(\mathrm{t})+\left(\mathrm{NP}+\mathrm{LC}-\mathrm{PA}_{0}\right) \mathrm{x}(\mathrm{t}) \\
& +\left(\mathrm{JC}-\mathrm{PA}_{1}\right) \mathrm{x}\left(\mathrm{t}-\tau_{0}\right) \\
& +\sum_{\mathrm{i}=0}^{\mathrm{k}}\left(\left(\mathrm{G}_{\mathrm{i}}-\mathrm{PB}_{\mathrm{i}}\right) \mathrm{u}\left(\mathrm{t}-\tau_{\mathrm{i}+1}\right)\right)-\operatorname{PDd}(\mathrm{t}) .
\end{aligned}
$$

If conditions (6) are satisfied, the error dynamics of the observer is expressed as $\dot{e}(\mathrm{t})=\mathrm{Ne}(\mathrm{t})$. FOUIO's convergence is then achieved if the LMI (5) is verified.

The determination of the matrices $\mathrm{N}, \mathrm{L}, \mathrm{J}$, and $\mathrm{P}$ from the first, second, and fourth equations of (6) is a difficult task because we have to calculate four matrices by using only three equations. In order to use the well-known results obtained for the classical full-order observer without unknown inputs [2], by means of the notation

$$
\mathrm{K}_{0}=\mathrm{L}+\mathrm{NE},
$$

the first term of (6) becomes

$$
\mathrm{N}=\mathrm{PA}_{0}-\mathrm{K}_{0} \mathrm{C}
$$

Now, using (11) and (12), the dynamics (2) can be written as

$$
\begin{aligned}
\dot{\zeta}(\mathrm{t})= & \left(\mathrm{PA}_{0}-\mathrm{K}_{0} \mathrm{C}\right) \zeta(\mathrm{t})+\mathrm{Ly}(\mathrm{t})+\mathrm{Jy}\left(\mathrm{t}-\tau_{0}\right) \\
& +\sum_{\mathrm{i}=0}^{\mathrm{k}} \mathrm{G}_{\mathrm{i}} \mathrm{u}\left(\mathrm{t}-\tau_{\mathrm{i}+1}\right), \\
\widehat{\mathrm{x}}(\mathrm{t})= & \zeta(\mathrm{t})-\operatorname{Ey}(\mathrm{t}) .
\end{aligned}
$$

If the pair $\left(\mathrm{PA}_{0}, \mathrm{C}\right)$ is not observable, the calculation of matrix $K_{0}$ is made such that the observer is asymptotically stable if and only if $\left(\mathrm{PA}_{0}, \mathrm{C}\right)$ is detectable [2]. By extending the approach from [2], we can conclude that the necessary and sufficient conditions to design a stable observer are given by the following theorem.

Theorem 3 (see [2]). For system (1), the full-order observer (13) exists if and only if (1) $\operatorname{rank}(\mathrm{CD})=\mathrm{q} ;(2) \operatorname{rank}\left[\begin{array}{c}\mathrm{sI}-\mathrm{PA}_{0} \\ \mathrm{C}\end{array}\right]=$ $\mathrm{n},(\forall) \mathbf{s} \in t, \operatorname{Re}(\mathbf{s}) \geq 0$.

Proof. The proof of the theorem is an extension of the approach from [2]. Because system (13) is in the form of a standard observer equation, then the matrix $\mathrm{K}_{0}$ can be calculated such that the observer (2) is asymptotically stable if and only if the pair $\left(\mathrm{PA}_{0}, \mathrm{C}\right)$ is observable. In [2], it is proved that the above condition (2) is equivalent with the pair $\left(\mathrm{PA}_{0}, \mathrm{C}\right)$ - observable or at least detectable (first existence condition of the full-order observer). The second constraint is the condition (1) from Theorem 3; bearing in mind the assumptions $\mathrm{A} 1$ and $\mathrm{A} 2$, as well as the dimensions of the matrices $\mathrm{C}$ and $\mathrm{D}$, this condition is always fulfilled. Therefore, up to this point in the design of the unknown input observer, the only existence condition of FOUIO is related to the observability or at least detectability of the pair $\left(\mathrm{PA}_{0}, \mathrm{C}\right)$.

To calculate $\mathrm{N}, \mathrm{L}, \mathrm{J}, \mathrm{P}, \mathrm{G}_{0}$, and $\mathrm{G}_{1}$, we partition matrices $\mathrm{A}_{0}, \mathrm{~A}_{1}, \mathrm{C}, \mathrm{N}, \mathrm{P}, \mathrm{L}$, and $\mathrm{J}$ as follows:

$$
\begin{aligned}
A_{0} & =\left[\begin{array}{ll}
A_{0(11)} & A_{0(12)} \\
A_{0(21)} & A_{0(22)}
\end{array}\right], \\
A_{1} & =\left[\begin{array}{ll}
A_{1(11)} & A_{1(12)} \\
A_{1(21)} & A_{1(22)}
\end{array}\right], \\
C^{T} & =\left[\begin{array}{l}
C_{1}^{T} \\
C_{2}^{T}
\end{array}\right], \\
N & =\left[\begin{array}{ll}
N_{11} & N_{12} \\
N_{21} & N_{22}
\end{array}\right], \\
P & =\left[\begin{array}{ll}
P_{11} & P_{12} \\
P_{21} & P_{22}
\end{array}\right],
\end{aligned}
$$




$$
\begin{gathered}
\mathrm{L}=\left[\begin{array}{l}
\mathrm{L}_{1} \\
\mathrm{~L}_{2}
\end{array}\right], \\
\mathrm{J}=\left[\begin{array}{l}
\mathrm{J}_{1} \\
\mathrm{~J}_{2}
\end{array}\right],
\end{gathered}
$$

where

$$
\mathrm{A}_{0} \in \mathscr{R}^{\mathrm{n} \times \mathrm{n}},
$$

$\mathrm{A}_{0(11)} \in \mathscr{R}^{(\mathrm{n}-\mathrm{p}) \times(\mathrm{n}-\mathrm{p})}$,

$\mathrm{A}_{0(12)} \in \mathscr{R}^{(\mathrm{n}-\mathrm{p}) \times \mathrm{p}}$,

$\mathrm{A}_{0(21)} \in \mathscr{R}^{\mathrm{p} \times(\mathrm{n}-\mathrm{p})}$,

$\mathrm{A}_{0(22)} \in \mathscr{R}^{\mathrm{p} \times \mathrm{p}}$,

$$
\mathrm{A}_{1} \in \mathscr{R}^{\mathrm{n} \times \mathrm{n}},
$$

$\mathrm{A}_{1(11)} \in \mathscr{R}^{(\mathrm{n}-\mathrm{p}) \times(\mathrm{n}-\mathrm{p})}$,

$\mathrm{A}_{1(12)} \in \mathscr{R}^{(\mathrm{n}-\mathrm{p}) \times \mathrm{p}}$,

$\mathrm{A}_{1(21)} \in \mathscr{R}^{\mathrm{p} \times(\mathrm{n}-\mathrm{p})}$,

$\mathrm{A}_{1(22)} \in \mathscr{R}^{\mathrm{p} \times \mathrm{p}}$,

$\mathrm{N} \in \mathscr{R}^{\mathrm{n} \times \mathrm{n}}$,

$\mathrm{N}_{11} \in \mathscr{R}^{(\mathrm{n}-\mathrm{p}) \times(\mathrm{n}-\mathrm{p})}$,

$\mathrm{N}_{12} \in \mathscr{R}^{(\mathrm{n}-\mathrm{p}) \times \mathrm{p}}$,

$\mathrm{N}_{21} \in \mathscr{R}^{\mathrm{p} \times(\mathrm{n}-\mathrm{p})}$,

$\mathrm{N}_{22} \in \mathscr{R}^{\mathrm{p} \times \mathrm{p}}$,

$\mathrm{P} \in \mathscr{R}^{\mathrm{n} \times \mathrm{n}}$,

$\mathrm{P}_{11} \in \mathscr{R}^{(\mathrm{n}-\mathrm{p}) \times(\mathrm{n}-\mathrm{p})}$,

$\mathrm{P}_{12} \in \mathscr{R}^{(\mathrm{n}-\mathrm{p}) \times \mathrm{p}}$,

$\mathrm{P}_{21} \in \mathscr{R}^{\mathrm{p} \times(\mathrm{n}-\mathrm{p})}$,

$\mathrm{P}_{22} \in \mathscr{R}^{\mathrm{p} \times \mathrm{p}}$,

$\mathrm{L} \in \mathscr{R}^{\mathrm{n} \times \mathrm{p}}$,

$\mathrm{L}_{1} \in \mathscr{R}^{(\mathrm{n}-\mathrm{p}) \times \mathrm{p}}$,

$\mathrm{L}_{2} \in \mathscr{R}^{\mathrm{p} \times \mathrm{p}}$,

$\mathrm{J} \in \mathscr{R}^{\mathrm{n} \times \mathrm{p}}$,

$\mathrm{J}_{1} \in \mathscr{R}^{(\mathrm{n}-\mathrm{p}) \times \mathrm{p}}$,

$\mathrm{J}_{2} \in \mathscr{R}^{\mathrm{p} \times \mathrm{p}}$,

$\mathrm{C} \in \mathscr{R}^{\mathrm{p} \times \mathrm{n}}$,

$$
\begin{aligned}
& \mathrm{C}_{1} \in \mathscr{R}^{\mathrm{p} \times(\mathrm{n}-\mathrm{p})}, \\
& \mathrm{C}_{2} \in \mathscr{R}^{\mathrm{p} \times \mathrm{p}} .
\end{aligned}
$$

The observer's design is concentrated into the following theorem.

Theorem 4. If the rank conditions in Theorem 3 are satisfied, the UIO (2) can be designed for system (1) as follows:

$$
\begin{aligned}
& \mathrm{E}=\mathrm{D}(\mathrm{CD})^{+} \mathrm{C}, \\
& \mathrm{P}=\mathrm{I}_{\mathrm{n}}-\mathrm{D}(\mathrm{CD})^{+} \mathrm{C}, \\
& \mathrm{G}_{\mathrm{i}}=\mathrm{PB}_{\mathrm{i}} \quad(\text { for } \mathrm{k}=0 \cdots \mathrm{k}), \\
& \mathrm{J}=\mathrm{PA}_{1} \mathrm{C}^{+},
\end{aligned}
$$

$\mathrm{N}$

$$
\begin{aligned}
& =\left[\begin{array}{ll}
\mathrm{N}_{11} & \left(\mathrm{~F}_{12}-\left(\mathrm{F}_{11}-\mathrm{F}_{12} \mathrm{P}_{22}^{-1} \mathrm{P}_{21}\right)\left(\mathrm{C}_{1}-\mathrm{C}_{2} \mathrm{P}_{22}^{-1} \mathrm{P}_{21}\right)^{+} \mathrm{C}_{2}\right) \mathrm{P}_{22}^{-1} \\
\mathrm{~N}_{21} & \left(\mathrm{~F}_{22}-\left(\mathrm{F}_{21}-\mathrm{F}_{22} \mathrm{P}_{22}^{-1} \mathrm{P}_{21}\right)\left(\mathrm{C}_{1}-\mathrm{C}_{2} \mathrm{P}_{22}^{-1} \mathrm{P}_{21}\right)^{+} \mathrm{C}_{2}\right) \mathrm{P}_{22}^{-1}
\end{array}\right], \\
& \mathrm{L}=\left[\begin{array}{l}
\left(\mathrm{F}_{11}-\mathrm{F}_{12} \mathrm{P}_{22}^{-1} \mathrm{P}_{21}\right)\left(\mathrm{C}_{1}-\mathrm{C}_{2} \mathrm{P}_{22}^{-1} \mathrm{P}_{21}\right)^{+} \\
\left(\mathrm{F}_{21}-\mathrm{F}_{22} \mathrm{P}_{22}^{-1} \mathrm{P}_{21}\right)\left(\mathrm{C}_{1}-\mathrm{C}_{2} \mathrm{P}_{22}^{-1} \mathrm{P}_{21}\right)^{+}
\end{array}\right],
\end{aligned}
$$

where

$$
\begin{aligned}
& \mathrm{F}_{11}=\mathrm{P}_{11} \mathrm{~A}_{0(11)}+\mathrm{P}_{12} \mathrm{~A}_{0(21)}-\mathrm{N}_{11} \mathrm{P}_{11}, \\
& \mathrm{~F}_{12}=\mathrm{P}_{11} \mathrm{~A}_{0(12)}+\mathrm{P}_{12} \mathrm{~A}_{0(22)}-\mathrm{N}_{11} \mathrm{P}_{12}, \\
& \mathrm{~F}_{21}=\mathrm{P}_{21} \mathrm{~A}_{0(11)}+\mathrm{P}_{22} \mathrm{~A}_{0(21)}-\mathrm{N}_{21} \mathrm{P}_{11}, \\
& \mathrm{~F}_{22}=\mathrm{P}_{21} \mathrm{~A}_{0(12)}+\mathrm{P}_{22} \mathrm{~A}_{0(22)}-\mathrm{N}_{21} \mathrm{P}_{21},
\end{aligned}
$$

while $\mathrm{N}_{11}$ and $\mathrm{N}_{21}$ are arbitrarily chosen; $\mathrm{P}_{22}$ should be a nonsingular matrix.

Proof. Since $\operatorname{rank}(\mathrm{CD})=\mathrm{q}$, i.e., the matrix $(\mathrm{CD})$ has full column rank, we can use the pseudoinverse of (CD), given by [17]: $(C D)^{+}=\left[(C D)^{\mathrm{T}}(C D)\right]^{-1}(C D)^{\mathrm{T}}$. By means of this pseudoinverse matrix, we can solve the fourth equation of $(6)$; one successively gets

$$
\begin{aligned}
(\mathrm{I}+\mathrm{EC}) \mathrm{D} & =0 \Longleftrightarrow \mathrm{D}+\mathrm{ECD}=0 \Longleftrightarrow \mathrm{E} \\
& =-\mathrm{D}(\mathrm{CD})^{+} .
\end{aligned}
$$

Hence, one gets $\mathrm{P}=\mathrm{I}_{\mathrm{n}}+\mathrm{EC}=\mathrm{I}_{\mathrm{n}}-\mathrm{D}(\mathrm{CD})^{+} \mathrm{C}$. Replacing $P$ into the third equation of (6), we obtain $G_{i}=P B_{i}=\left(I_{n}-\right.$ $\left.\mathrm{D}(\mathrm{CD})^{+} \mathrm{C}\right) \mathrm{B}_{\mathrm{i}}$. Now, substituting (14) into the first equation of (6), we obtain

$$
\begin{aligned}
& \mathrm{N}_{11} \mathrm{P}_{11}+\mathrm{N}_{12} \mathrm{P}_{21}+\mathrm{L}_{1} \mathrm{C}_{1}-\mathrm{P}_{11} \mathrm{~A}_{0(11)}-\mathrm{P}_{12} \mathrm{~A}_{0(21)} \\
& \quad=0{ }_{(\mathrm{n}-\mathrm{p}) \times(\mathrm{n}-\mathrm{p})}, \\
& \mathrm{N}_{11} \mathrm{P}_{12}+\mathrm{N}_{12} \mathrm{P}_{22}+\mathrm{L}_{1} \mathrm{C}_{2}-\mathrm{P}_{11} \mathrm{~A}_{0(12)}-\mathrm{P}_{12} \mathrm{~A}_{0(22)} \\
& \quad=0_{(\mathrm{n}-\mathrm{p}) \times \mathrm{p}}, \\
& \mathrm{N}_{21} \mathrm{P}_{11}+\mathrm{N}_{22} \mathrm{P}_{21}+\mathrm{L}_{2} \mathrm{C}_{1}-\mathrm{P}_{21} \mathrm{~A}_{0(11)}-\mathrm{P}_{22} \mathrm{~A}_{0(21)} \\
& \quad=0_{\mathrm{p} \times(\mathrm{n}-\mathrm{p})},
\end{aligned}
$$




$$
\begin{aligned}
& \mathrm{N}_{21} \mathrm{P}_{12}+\mathrm{N}_{22} \mathrm{P}_{22}+\mathrm{L}_{2} \mathrm{C}_{2}-\mathrm{P}_{21} \mathrm{~A}_{0(12)}-\mathrm{P}_{22} \mathrm{~A}_{0(22)} \\
& \quad=0_{\mathrm{p} \times \mathrm{p}}
\end{aligned}
$$

By using (17), system (19) is divided into the following systems:

$$
\begin{aligned}
& \mathrm{N}_{12} \mathrm{P}_{21}+\mathrm{L}_{1} \mathrm{C}_{1}=\mathrm{F}_{11}, \\
& \mathrm{~N}_{12} \mathrm{P}_{22}+\mathrm{L}_{1} \mathrm{C}_{2}=\mathrm{F}_{12}, \\
& \mathrm{~N}_{22} \mathrm{P}_{22}+\mathrm{L}_{2} \mathrm{C}_{2}=\mathrm{F}_{22}, \\
& \mathrm{~N}_{22} \mathrm{P}_{21}+\mathrm{L}_{2} \mathrm{C}_{1}=\mathrm{F}_{21} .
\end{aligned}
$$

Working in the hypothesis: the matrix $\left(\mathrm{C}_{1}-\mathrm{C}_{2} \mathrm{P}_{22}^{-1} \mathrm{P}_{21}\right) \epsilon$ $\mathscr{R}^{\mathrm{p} \times(\mathrm{n}-\mathrm{p})}$ is full column rank. By solving systems (20) and (21), we obtain

$$
\begin{aligned}
\mathrm{L}_{1} & =\left(\mathrm{F}_{11}-\mathrm{F}_{12} \mathrm{P}_{22}^{-1} \mathrm{P}_{21}\right)\left(\mathrm{C}_{1}-\mathrm{C}_{2} \mathrm{P}_{22}^{-1} \mathrm{P}_{21}\right)^{+}, \\
\mathrm{L}_{2} & =\left(\mathrm{F}_{21}-\mathrm{F}_{22} \mathrm{P}_{22}^{-1} \mathrm{P}_{21}\right)\left(\mathrm{C}_{1}-\mathrm{C}_{2} \mathrm{P}_{22}^{-1} \mathrm{P}_{21}\right)^{+}, \\
\mathrm{N}_{12} & =\left(\mathrm{F}_{12}\right. \\
& \left.-\left(\mathrm{F}_{11}-\mathrm{F}_{12} \mathrm{P}_{22}^{-1} \mathrm{P}_{21}\right)\left(\mathrm{C}_{1}-\mathrm{C}_{2} \mathrm{P}_{22}^{-1} \mathrm{P}_{21}\right)^{+} \mathrm{C}_{2}\right) \mathrm{P}_{22}^{-1}, \\
\mathrm{~N}_{22} & =\left(\mathrm{F}_{22}\right. \\
& \left.-\left(\mathrm{F}_{21}-\mathrm{F}_{22} \mathrm{P}_{22}^{-1} \mathrm{P}_{21}\right)\left(\mathrm{C}_{1}-\mathrm{C}_{2} \mathrm{P}_{22}^{-1} \mathrm{P}_{21}\right)^{+} \mathrm{C}_{2}\right) \mathrm{P}_{22}^{-1} .
\end{aligned}
$$

Now, solving the second equation of (6), we get

$$
\mathrm{J}=\mathrm{PA}_{1} \mathrm{C}^{+} \text {. }
$$

The unknown matrices of the FOUIO (2), i.e., N, L, J, $P$, and $G_{i}$, have been successfully determined with respect to the arbitrarily chosen matrices $\mathrm{N}_{11}$ and $\mathrm{N}_{21}$. According to Theorem 2, the obtained matrix $\mathrm{N}$ should satisfy two constraints: (1) there exists a symmetric and positive-definite matrix $\mathrm{R} \in \mathscr{R}^{\mathrm{n} \times \mathrm{n}}$ which verifies the LMI (5), i.e., the matrix $\mathrm{N}$ is Hurwitz; (2) the pair $\left(\mathrm{PA}_{0}, \mathrm{C}\right)$ is observable. If these two conditions are satisfied, the matrix $\mathrm{N}$ has been obtained properly, the dynamics of the observer error has an homogeneous form, and $\mathrm{e}(\mathrm{t}) \longrightarrow 0$ as $\mathrm{t} \longrightarrow \infty$ with an arbitrary convergence rate for any $\mathrm{x}(0), \mathrm{d}(\mathrm{t})$, and $\mathrm{u}(\mathrm{t})$. Otherwise, other matrices $\mathrm{N}_{11}, \mathrm{~N}_{21}$ are chosen, the matrices from (17) are again calculated, and systems (20) and (21) are solved until the above presented constraints are fulfilled. In fact, no condition regarding the observability or detectability of the pairs $\left(\mathrm{PA}_{0}, \mathrm{C}\right)$ is required in our design approach. Therefore, the unique existence condition of the observer is $\operatorname{rank}(C D)=\mathrm{q}$. The theorem's proof is now complete.

The algorithm associated to the delay-dependent observer is summarized below.

\section{Algorithm 5. Design of FOUIO}

Step 1. Given system (1), verify the related assumptions A1A3.
Step 2. If the existence conditions given in Theorem 3 hold, one calculates the generalized inverse matrix $(C D)^{+}$related to the matrix $\mathrm{CD}$. By using it, one computes the matrix $\mathrm{E}$ by means of the first equation of (16); then, one computes the matrices $P, G_{0}$, and $G_{1}$ with the second, third, and fourth equations of (16), respectively.

Step 3. One partitions the matrices $\mathrm{A}_{0}, \mathrm{~A}_{1}, \mathrm{C}, \mathrm{N}, \mathrm{P}, \mathrm{L}$, and J according to (14).

Step 4. Matrices $\mathrm{N}_{11}$ and $\mathrm{N}_{21}$ are arbitrarily chosen; the matrices from (17) are determined.

Step 5. One solves systems (20) and (21); after that, the matrices $\mathrm{N}, \mathrm{L}$, and $\mathrm{J}$ are built.

Step 6. Using the obtained matrix $\mathrm{N}$, if the required constraints are satisfied, then (1) the matrix $\mathrm{N}$ is Hurwitz, i.e., there exists a symmetric and positive-definite matrix $\mathrm{R} \in \mathscr{R}^{\mathrm{n} \times \mathrm{n}}$ verifying the LMI (5); (2) the pair $\left(\mathrm{PA}_{0}, \mathrm{C}\right)$ is observable or at least detectable; the matrix $\mathrm{N}$ has been obtained properly; otherwise, Steps 4-6 are repeated (in a "while" loop) until these conditions are fulfilled. Bearing in mind that there is no risk for infinite "while" loop, there can be concluded that the FOUIO's design algorithm has no existence conditions, being characterized by lack of a priori restrictions on the class of systems to be considered.

Step 7. The observer described by (2) is completely designed and the time history of the system's estimated states can be obtained.

\section{Design of the Reduced-Order Observer}

Theorem 6. Consider the LTI multivariable system (1) with multiple delays under the five assumptions (A4-A8) presented above; the ROUIO (3) is asymptotically stable, if and only if there exist symmetric and positive-definite matrix $\overline{\mathrm{R}} \in \mathscr{R}^{\text {s×s }}$ verifying the LMI:

$$
\widetilde{\mathrm{N}}^{\mathrm{T}} \overline{\mathrm{R}}+\overline{\mathrm{R}} \widetilde{\mathrm{N}}<0,
$$

with $\widetilde{\boldsymbol{N}}=\boldsymbol{Z}^{-1} \overline{\boldsymbol{N}}$, and if there exists a vector $\bar{\zeta}(\mathrm{t})=\mathrm{Fx}(\mathrm{t})$ such that the next conditions are satisfied:

$$
\begin{aligned}
\overline{\mathrm{N}}+\overline{\mathrm{L} C}-\mathrm{ZFA}_{0} & =0, \\
\overline{\mathrm{J}} \mathrm{C}-\mathrm{ZFA}_{1} & =0, \\
\overline{\mathrm{G}}_{\mathrm{i}}-\mathrm{ZFB}_{\mathrm{i}} & =0 \quad \forall \mathrm{i}=0 \cdots \mathrm{k}, \\
\mathrm{ZFD} & =0, \\
\overline{\mathrm{E}} \mathrm{C}+\mathrm{HF} & =\mathrm{I}_{\mathrm{n}} ;
\end{aligned}
$$

Proof. Define the observer error vector defined as the difference between the estimated vector $\widehat{\bar{\zeta}}(\mathrm{t})$ described by (3) and the state vector related to system (1) as

$$
\overline{\mathrm{e}}(\mathrm{t})=\hat{\bar{\zeta}}(\mathrm{t})-\bar{\zeta}(\mathrm{t})
$$


Using (1), (3), and (4), the dynamics of the estimation error becomes

$$
\begin{aligned}
\mathrm{Z} \dot{\overline{\mathrm{e}}}(\mathrm{t})= & \overline{\mathrm{N}} \overline{\mathrm{e}}(\mathrm{t})+\left[\overline{\mathrm{N}} \mathrm{F}-\mathrm{ZFA}_{0}+\overline{\mathrm{L} C}\right] \mathrm{x}(\mathrm{t}) \\
& +\left[\overline{\mathrm{J} C}-\mathrm{ZFA}_{1}\right] \mathrm{x}\left(\mathrm{t}-\tau_{0}\right) \\
& +\sum_{\mathrm{i}=0}^{\mathrm{k}}\left(\left[\overline{\mathrm{G}}_{\mathrm{i}}-\mathrm{ZFB}_{\mathrm{i}}\right] \mathrm{u}\left(\mathrm{t}-\tau_{\mathrm{i}+1}\right)\right)-\mathrm{ZFDd}(\mathrm{t}) .
\end{aligned}
$$

If $\overline{\mathrm{N}} \mathrm{F}+\overline{\mathrm{L} C}-\mathrm{ZFA}_{0}=0, \overline{\mathrm{J}} \mathrm{C}-\mathrm{ZFA}_{1}=0, \overline{\mathrm{G}}_{\mathrm{i}}-\mathrm{ZFB}_{\mathrm{i}}=0 \forall \mathrm{i}=$ $0 \cdots \mathrm{k}, \mathrm{ZFD}=0$ the error dynamics (27) can be written as

$$
\dot{\overline{\mathrm{e}}}(\mathrm{t})=\widetilde{\mathrm{N}} \overline{\mathrm{e}}(\mathrm{t}) \text {, }
$$

where $\widetilde{N}=Z^{-1} \bar{N}$.

Let the state estimation error be defined as $e_{x}(t)=\widehat{x}(t)-$ $x(t)$. From (1) and (3), one obtains $e_{x}(t)=\left(H F-I_{n}+\bar{E} C\right) x(t)$. If $\mathrm{HF}-\mathrm{I}_{\mathrm{n}}+\overline{\mathrm{E} C}=0, \mathrm{e}_{\mathrm{x}}(\mathrm{t})=0$ for any $\mathrm{x}(\mathrm{t})$ results.

Furthermore, if condition (24) is satisfied then the observer's error dynamics (28) is asymptotically stable. Now, the proof of the Theorem 6 is complete.

To compute the matrices F, Z, $\overline{\mathrm{E}}, \overline{\mathrm{N}}, \overline{\mathrm{L}}, \overline{\mathrm{J}}, \mathrm{H}, \overline{\mathrm{G}}_{0}$, and $\overline{\mathrm{G}}_{1}$, let us partition the matrices $A_{0}, A_{1}, C, \bar{N}, H, \bar{L}, \bar{J}, F, Z$, and $D$ as follows:

$$
\begin{aligned}
& A_{0}=\left[\begin{array}{ll}
A_{0(11)} & A_{0(12)} \\
A_{0(21)} & A_{0(22)}
\end{array}\right], \\
& A_{1}=\left[\begin{array}{ll}
A_{1(11)} & A_{1(12)} \\
A_{1(21)} & A_{1(22)}
\end{array}\right] \text {, } \\
& \mathrm{C}=\left[\begin{array}{ll}
\mathrm{C}_{1} & 0_{\mathrm{p} \times \mathrm{q}}
\end{array}\right]=\left[\begin{array}{ll}
\widetilde{\mathrm{C}}_{1} & \widetilde{\mathrm{C}}_{2}
\end{array}\right] \text {, } \\
& \mathrm{D}=\left[\begin{array}{l}
\mathrm{D}_{1} \\
\mathrm{D}_{2}
\end{array}\right] \text {, } \\
& \overline{\mathrm{N}}=\left[\begin{array}{ll}
\overline{\mathrm{N}}_{11} & \overline{\mathrm{N}}_{11} \\
\overline{\mathrm{N}}_{21} & \overline{\mathrm{N}}_{22}
\end{array}\right]=\left[\begin{array}{ll}
\overline{\mathrm{N}}_{1} & \overline{\mathrm{N}}_{2}
\end{array}\right] \text {, } \\
& \mathrm{H}=\left[\begin{array}{ll}
\mathrm{H}_{11} & \mathrm{H}_{11} \\
\mathrm{H}_{21} & \mathrm{H}_{22}
\end{array}\right] \text {, } \\
& \overline{\mathrm{L}}=\left[\begin{array}{l}
\overline{\mathrm{L}}_{1} \\
\overline{\mathrm{L}}_{2}
\end{array}\right], \\
& \overline{\mathrm{J}}=\left[\begin{array}{l}
\overline{\mathrm{J}}_{1} \\
\overline{\mathrm{J}}_{2}
\end{array}\right] \text {, } \\
& \overline{\mathrm{E}}=\left[\begin{array}{l}
\overline{\mathrm{E}}_{1} \\
\overline{\mathrm{E}}_{2}
\end{array}\right], \\
& \mathrm{F}=\left[\begin{array}{ll}
\mathrm{F}_{11} & \mathrm{~F}_{12} \\
\mathrm{~F}_{21} & \mathrm{~F}_{22}
\end{array}\right]=\left[\begin{array}{cc}
0_{\mathrm{p} \times \mathrm{q}} & \mathrm{I}_{\mathrm{p} \times \mathrm{p}} \\
0_{(s-\mathrm{p}) \times \mathrm{q}} & 0_{(s-\mathrm{p}) \times \mathrm{p}}
\end{array}\right] \text {, } \\
& Z=\left[\begin{array}{ll}
Z_{11} & Z_{12} \\
Z_{21} & Z_{22}
\end{array}\right]=\left[\begin{array}{ll}
Z_{1} & Z_{2}
\end{array}\right] \text {, }
\end{aligned}
$$

$$
\begin{aligned}
& Z_{1}=\left[\begin{array}{l}
Z_{11} \\
Z_{21}
\end{array}\right], \\
& Z_{2}=\left[\begin{array}{l}
Z_{12} \\
Z_{22}
\end{array}\right],
\end{aligned}
$$

where

$$
\mathrm{A}_{0} \in \mathscr{R}^{\mathrm{n} \times \mathrm{n}},
$$

$\mathrm{A}_{0(11)} \in \mathscr{R}^{\mathrm{q} \times \mathrm{q}}$,

$\mathrm{A}_{0(12)} \in \mathscr{R}^{\mathrm{q} \times \mathrm{p}}$,

$\mathrm{A}_{0(21)} \in \mathscr{R}^{\mathrm{p} \times \mathrm{q}}$,

$\mathrm{A}_{0(22)} \in \mathscr{R}^{\mathrm{p} \times \mathrm{p}}$,

$\mathrm{A}_{1} \in \mathscr{R}^{\mathrm{n} \times \mathrm{n}}$,

$\mathrm{A}_{1(11)} \in \mathscr{R}^{\mathrm{q} \times \mathrm{q}}$,

$\mathrm{A}_{1(12)} \in \mathscr{R}^{\mathrm{q} \times \mathrm{p}}$,

$\mathrm{A}_{1(21)} \in \mathscr{R}^{\mathrm{p} \times \mathrm{q}}$,

$\mathrm{A}_{1(22)} \in \mathscr{R}^{\mathrm{p} \times \mathrm{p}}$,

$\overline{\mathrm{N}} \in \mathscr{R}^{\mathrm{s} \times s}$,

$\overline{\mathrm{N}}_{11} \in \mathscr{R}^{\mathrm{q} \times \mathrm{p}}$,

$\overline{\mathrm{N}}_{12} \in \mathscr{R}^{\mathrm{q} \times(\mathrm{s}-\mathrm{p})}$,

$\overline{\mathrm{N}}_{21} \in \mathscr{R}^{(\mathrm{s}-\mathrm{q}) \times \mathrm{p}}$,

$\overline{\mathrm{N}}_{22} \in \mathscr{R}^{(\mathrm{s}-\mathrm{q}) \times(\mathrm{s}-\mathrm{p})}$,

$\mathrm{H} \in \mathscr{R}^{\mathrm{n} \times \mathrm{s}}$,

$\mathrm{H}_{11} \in \mathscr{R}^{\mathrm{q} \times \mathrm{p}}$,

$\mathrm{H}_{12} \in \mathscr{R}^{\mathrm{q} \times(\mathrm{s}-\mathrm{p})}$,

$\mathrm{H}_{21} \in \mathscr{R}^{\mathrm{p} \times \mathrm{p}}$,

$\mathrm{H}_{22} \in \mathscr{R}^{\mathrm{p} \times(\mathrm{s}-\mathrm{p})}$,

$\overline{\mathrm{L}} \in \mathscr{R}^{\mathrm{s} \times \mathrm{p}}$,

$\overline{\mathrm{L}}_{1} \in \mathscr{R}^{\mathrm{q} \times \mathrm{p}}$,

$\overline{\mathrm{L}}_{2} \in \mathscr{R}^{(\mathrm{s}-\mathrm{q}) \times \mathrm{p}}$,

$\overline{\mathrm{J}} \in \mathscr{R}^{\mathrm{s \times p}}$,

$\overline{\mathrm{J}}_{1} \in \mathscr{R}^{\mathrm{q} \times \mathrm{p}}$,

$\overline{\mathrm{J}}_{2} \in \mathscr{R}^{(\mathrm{s}-\mathrm{q}) \times \mathrm{p}}$,

$\overline{\mathrm{E}} \in \mathscr{R}^{\mathrm{n} \times \mathrm{p}}$, 


$$
\begin{aligned}
& \overline{\mathrm{E}}_{1} \in \mathscr{R}^{\mathrm{q} \times \mathrm{p}}, \\
& \overline{\mathrm{E}}_{2} \in \mathscr{R}^{\mathrm{p} \times \mathrm{p}} \text {, } \\
& \mathrm{D} \in \mathscr{R}^{\mathrm{n} \times \mathrm{q}} \text {, } \\
& \mathrm{D}_{1} \in \mathscr{R}^{\mathrm{q} \times \mathrm{q}} \text {, } \\
& \mathrm{D}_{2} \in \mathscr{R}^{\mathrm{p} \times \mathrm{q}} \text {, } \\
& \mathrm{Z} \in \mathscr{R}^{\mathrm{s} \times \mathrm{s}} \text {, } \\
& \mathrm{Z}_{11} \in \mathscr{R}^{\mathrm{q} \times \mathrm{p}} \text {, } \\
& \mathrm{Z}_{12} \in \mathscr{R}^{\mathrm{q} \times(\mathrm{s}-\mathrm{p})} \text {, } \\
& \mathrm{Z}_{21} \in \mathscr{R}^{(\mathrm{s}-\mathrm{q}) \times \mathrm{p}} \text {, } \\
& \mathrm{Z}_{22} \in \mathscr{R}^{(\mathrm{s}-\mathrm{q}) \times(\mathrm{s}-\mathrm{p})} \text {, } \\
& \mathrm{Z}_{1} \in \mathscr{R}^{\mathrm{s} \times \mathrm{p}} \text {, } \\
& \mathrm{Z}_{2} \in \mathscr{R}^{\mathrm{s} \times(\mathrm{s}-\mathrm{p})} \text {, } \\
& \overline{\mathrm{N}}_{1} \in \mathscr{R}^{\mathrm{s} \times \mathrm{p}}, \\
& \overline{\mathrm{N}}_{2} \in \mathscr{R}^{\mathrm{s} \times(\mathrm{s}-\mathrm{p})} \text {, } \\
& \mathrm{C} \in \mathscr{R}^{\mathrm{p} \times \mathrm{n}} \text {, } \\
& \mathrm{C}_{1} \in \mathscr{R}^{\mathrm{p} \times \mathrm{p}}, \\
& \widetilde{\mathrm{C}}_{1} \in \mathscr{R}^{\mathrm{p} \times \mathrm{q}} \text {, } \\
& \widetilde{\mathrm{C}}_{2} \in \mathscr{R}^{\mathrm{p} \times \mathrm{p}} \text {. }
\end{aligned}
$$

The ROUIO's design is concentrated into the following theorem.

Theorem 7. Consider the LTI multivariable (1) under the assumptions A4-A8; the ROUIO (3) is asymptotically stable if and only if the following conditions are satisfied: (1) there exists the matrix $\overline{\mathrm{R}}>0$ verifying the LMI (24); (2) the matrices $\overline{\mathrm{G}}_{0}, \overline{\mathrm{G}}_{1}, \overline{\mathrm{N}}, \overline{\mathrm{L}}, \overline{\mathrm{J}}, \overline{\mathrm{E}}$, and $\mathrm{H}$ are given by

$$
\begin{aligned}
\mathrm{Z}_{1} & =\mathrm{I}_{\mathrm{s} \times \mathrm{p}}-\overline{\mathrm{D}}_{2}\left(\mathrm{C}_{1} \mathrm{D}_{2}\right)^{+} \mathrm{C}_{1}, \\
\overline{\mathrm{G}}_{\mathrm{i}} & =\left[\begin{array}{lll}
0_{\mathrm{s} \times \mathrm{q}} & \mathrm{Z}_{1}
\end{array}\right] \mathrm{B}_{\mathrm{i}} \quad \forall \mathrm{i}=1 \cdots \mathrm{k}, \\
\overline{\mathrm{N}} & =\left[\begin{array}{ll}
\mathrm{Z}_{1}\left(\mathrm{~A}_{0(14)}-\mathrm{A}_{0(13)} \widetilde{\mathrm{C}}_{1}^{+} \widetilde{\mathrm{C}}_{2}\right) & \overline{\mathrm{N}}_{2}
\end{array}\right], \\
\overline{\mathrm{L}} & =\mathrm{Z}_{1} \mathrm{~A}_{0(21)} \widetilde{\mathrm{C}}_{1}^{+}, \\
\overline{\mathrm{J}} & =\left(\mathrm{ZFA}_{1}\right) \mathrm{C}^{+}, \\
\overline{\mathrm{E}} & =\left[\begin{array}{c}
\widetilde{\mathrm{C}}_{1}^{+} \\
\mathrm{I}_{\mathrm{P}}-\widetilde{\mathrm{C}}_{1}\left(\mathrm{C}_{1} \widetilde{\mathrm{C}}_{1}\right)^{+} \mathrm{C}_{1}
\end{array}\right], \\
\mathrm{H} & =\left[\begin{array}{c}
-\widetilde{\mathrm{C}}_{1}^{+} \widetilde{\mathrm{C}}_{2} \\
\mathrm{I}_{\mathrm{p}}-\widetilde{\mathrm{C}}_{2}+\widetilde{\mathrm{C}}_{1}\left(\mathrm{C}_{1} \widetilde{\mathrm{C}}_{1}\right)^{+} \mathrm{C}_{1} \widetilde{\mathrm{C}}_{2} 0_{\mathrm{p} \times(\mathrm{s}-\mathrm{p})}
\end{array}\right],
\end{aligned}
$$

where the matrices $\mathrm{Z}_{2} \in \mathscr{R}^{\mathrm{s} \times(\mathrm{s}-\mathrm{p})}$ and $\overline{\mathrm{N}}_{2} \in \mathscr{R}^{\mathrm{s} \times(\mathrm{s}-\mathrm{p})}$ are arbitrarily chosen, $\widetilde{\mathrm{C}}_{1} \in \mathscr{R}^{\mathrm{p} \times \mathrm{q}}$ and $\widetilde{\mathrm{C}}_{2} \in \mathscr{R}^{\mathrm{p} \times \mathrm{p}}$ are submatrices of the matrix $\mathrm{C}$, and $\overline{\mathrm{D}}_{2}=\mathrm{I}_{\mathrm{s} \times \mathrm{p}} \mathrm{D}_{2}$.

Proof. Using (29) and (30), the fourth equation of (25) becomes

$$
\mathrm{Z}_{1} \mathrm{D}_{2}=0_{\mathrm{s} \times \mathrm{q}} .
$$

To compute the matrix $Z_{1}$ from this equation, one can choose

$$
\mathrm{Z}_{1}=\mathrm{I}_{\mathrm{s} \times \mathrm{p}}+\mathrm{T}_{1} \mathrm{C}_{1}
$$

with $\mathrm{T}_{1} \in \mathscr{R}^{\mathrm{s} \times \mathrm{p}}$ an unknown matrix to be computed. With the notation $\overline{\mathrm{D}}_{2}=\mathrm{I}_{\mathrm{s} \times \mathrm{p}} \mathrm{D}_{2}$, one gets $\mathrm{T}_{1}=-\overline{\mathrm{D}}_{2}\left(\mathrm{C}_{1} \mathrm{D}_{2}\right)^{+}$, where $\left(\mathrm{C}_{1} \mathrm{D}_{2}\right)^{+}$is the generalized pseudoinverse of $\left(\mathrm{C}_{1} \mathrm{D}_{2}\right)$, given by $\left(\mathrm{C}_{1} \mathrm{D}_{2}\right)^{+}=\left[\left(\mathrm{C}_{1} \mathrm{D}_{2}\right)^{\mathrm{T}}\left(\mathrm{C}_{1} \mathrm{D}_{2}\right)\right]^{-1}\left(\mathrm{C}_{1} \mathrm{D}_{2}\right)^{\mathrm{T}}$. According to the assumption $\mathrm{A} 5$ and to the fact that the matrix $\mathrm{C}_{1}$ is full rank, we can conclude that $\operatorname{rank}\left(\mathrm{C}_{1} \mathrm{D}_{2}\right)=\mathrm{q}$, and the generalized pseudoinverse of $\left(\mathrm{C}_{1} \mathrm{D}_{2}\right)$ can be always obtained.

Equation (33) can be then written as

$$
\mathrm{Z}_{1}=\mathrm{I}_{\mathrm{s} \times \mathrm{p}}-\overline{\mathrm{D}}_{2}\left(\mathrm{C}_{1} \mathrm{D}_{2}\right)^{+} \mathrm{C}_{1},
$$

and the matrix $\mathrm{Z}_{2} \in \mathscr{R}^{\mathrm{s} \times(\mathrm{s}-\mathrm{p})}$ is chosen arbitrarily.

Now, using the expression of the matrix $Z$, we obtain the matrices $\bar{G}_{i}$ in the third equation of (25). We arbitrarily choose the matrices $\mathrm{N}_{12}$ and $\mathrm{N}_{22}$; as a consequence, the matrix $\overline{\mathrm{N}}_{2}$ is arbitrarily chosen. Using this as well as the form of matrix $\mathrm{C}$ given in (29) and (30), i.e., $\mathrm{C}=\left[\begin{array}{ll}\mathrm{C}_{1} & 0_{\mathrm{p} \times \mathrm{q}}\end{array}\right]=$ $\left[\begin{array}{ll}\widetilde{\mathrm{C}}_{1} & \widetilde{\mathrm{C}}_{2}\end{array}\right]$, the first equation (25) can be written in a form of matrix system as follows:

$$
\begin{gathered}
-\mathrm{Z}_{11} \mathrm{~A}_{0(21)}+\overline{\mathrm{L}}_{1} \widetilde{\mathrm{C}}_{1}=0_{\mathrm{q} \times \mathrm{q}}, \\
\overline{\mathrm{N}}_{11}-\mathrm{Z}_{11} \mathrm{~A}_{0(22)}+\overline{\mathrm{L}}_{1} \widetilde{\mathrm{C}}_{2}=0_{\mathrm{q} \times \mathrm{p}}, \\
-\mathrm{Z}_{21} \mathrm{~A}_{0(21)}+\overline{\mathrm{L}}_{2} \widetilde{\mathrm{C}}_{1}=0_{(\mathrm{s}-\mathrm{q}) \times \mathrm{q}}, \\
\overline{\mathrm{N}}_{21}-\mathrm{Z}_{21} \mathrm{~A}_{0(22)}+\overline{\mathrm{L}}_{2} \widetilde{\mathrm{C}}_{2}=0_{(\mathrm{s}-\mathrm{q}) \times \mathrm{p}} ;
\end{gathered}
$$

by solving system (35), we obtain

$$
\begin{aligned}
\overline{\mathrm{N}}_{11} & =\mathrm{Z}_{11}\left(\mathrm{~A}_{0(22)}-\mathrm{A}_{0(21)} \widetilde{\mathrm{C}}_{1}^{+} \widetilde{\mathrm{C}}_{2}\right), \\
\overline{\mathrm{L}}_{1} & =\mathrm{Z}_{11} \mathrm{~A}_{0(21)} \widetilde{\mathrm{C}}_{1}^{+}, \\
\overline{\mathrm{N}}_{21} & =\mathrm{Z}_{21}\left(\mathrm{~A}_{0(22)}-\mathrm{A}_{0(21)} \widetilde{\mathrm{C}}_{1}^{+} \widetilde{\mathrm{C}}_{2}\right), \\
\overline{\mathrm{L}}_{2} & =\mathrm{Z}_{21} \mathrm{~A}_{0(21)} \widetilde{\mathrm{C}}_{1}^{+} ;
\end{aligned}
$$

bearing in mind the fact that $\mathrm{q}<\mathrm{p}$, it results that $\widetilde{\mathrm{C}}_{1}$ is a submatrix of the nonsingular matrix $\mathrm{C}_{1}$; from this, one deduces that $\operatorname{rank}\left(\widetilde{\mathrm{C}}_{1}\right)=$ q, i.e., $\widetilde{\mathrm{C}}_{1}$ is a full column rank matrix.

Now, solving the second equation of (25), we get

$$
\bar{J}=\left(\mathrm{ZFA}_{1}\right) \mathrm{C}^{+} \text {. }
$$




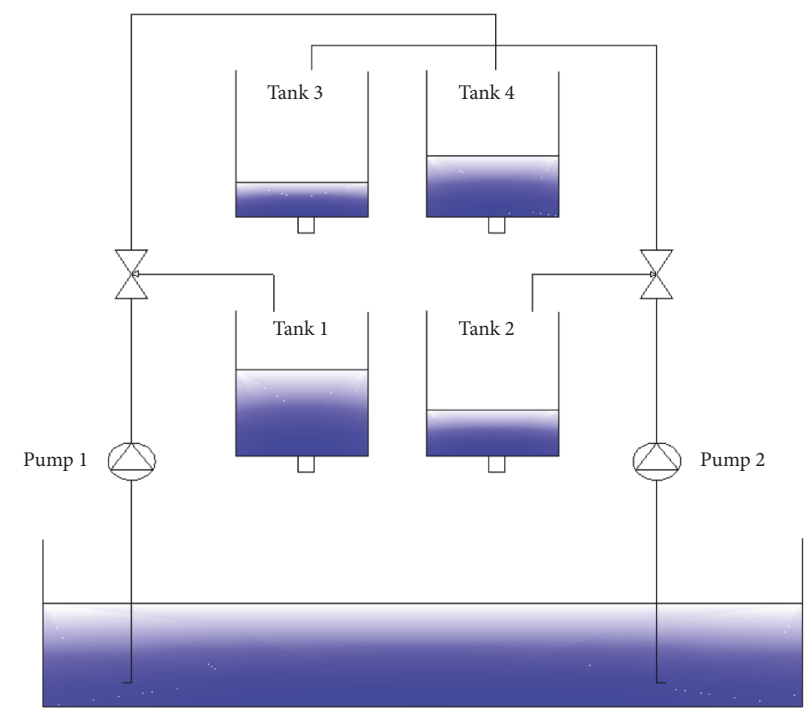

FIGURE 1: The quadruple-tank process.

Using (29) and (30), the sixth equation (25) can be transformed into a matrix system as

$$
\begin{aligned}
\overline{\mathrm{E}}_{1} \widetilde{\mathrm{C}}_{1} & =\mathrm{I}_{\mathrm{q}}, \\
\overline{\mathrm{E}}_{1} \widetilde{\mathrm{C}}_{2}+\mathrm{H}_{11} & =0_{\mathrm{q} \times \mathrm{p}}, \\
\overline{\mathrm{E}}_{2} \widetilde{\mathrm{C}}_{1} & =0_{\mathrm{p} \times \mathrm{q}}, \\
\overline{\mathrm{E}}_{2} \widetilde{\mathrm{C}}_{2}+\mathrm{H}_{21} & =\mathrm{I}_{\mathrm{p}} ;
\end{aligned}
$$

from the first and second equations of (38), we obtain $\overline{\mathrm{E}}_{1}=\widetilde{\mathrm{C}}_{1}^{+}$ and $\mathrm{H}_{11}=-\overline{\mathrm{E}}_{1} \widetilde{\mathrm{C}}_{2}=-\widetilde{\mathrm{C}}_{1}^{+} \widetilde{\mathrm{C}}_{2}$. On the other hand, the matrix $\overline{\mathrm{E}}_{2}$ is calculated from the third equation of (35) as follows:

$$
\overline{\mathrm{E}}_{2}=\mathrm{I}_{\mathrm{p}}+\mathrm{T}_{2} \mathrm{C}_{1} \text {, }
$$

where $\mathrm{T}_{2} \in \mathscr{R}^{\mathrm{p} \times \mathrm{p}}$ is an unknown matrix to be computed. Because $\mathrm{C}_{1} \in \mathscr{R}^{\mathrm{p} \times \mathrm{p}}$ is a nonsingular matrix and $\operatorname{rank}\left(\widetilde{\mathrm{C}}_{1}\right)=$ $\mathrm{q}$, one gets $\operatorname{rank}\left(\mathrm{C}_{1} \widetilde{\mathrm{C}}_{1}\right)=$ q, i.e., $\left(\mathrm{C}_{1} \widetilde{\mathrm{C}}_{1}\right)$ is a full column rank matrix. Taking this into account, one successively gets $\mathrm{T}_{2}=-\widetilde{\mathrm{C}}_{1}\left(\mathrm{C}_{1} \widetilde{\mathrm{C}}_{1}\right)^{+}$and $\overline{\mathrm{E}}_{2}=\mathrm{I}_{\mathrm{p}}-\widetilde{\mathrm{C}}_{1}\left(\mathrm{C}_{1} \widetilde{\mathrm{C}}_{1}\right)^{+} \mathrm{C}_{1}$. From the fourth equation of system (38), we obtain $\mathrm{H}_{12}=\mathrm{I}_{\mathrm{p}}-$ $\widetilde{\mathrm{C}}_{2}+\widetilde{\mathrm{C}}_{1}\left(\mathrm{C}_{1} \widetilde{\mathrm{C}}_{1}\right)^{+} \mathrm{C}_{1} \widetilde{\mathrm{C}}_{2}$; by concatenation of the matrices $\overline{\mathrm{E}}_{1}, \overline{\mathrm{E}}_{2}, \mathrm{H}_{11}, \mathrm{H}_{21}, \mathrm{H}_{12}=0_{\mathrm{q} \times(\mathrm{s}-\mathrm{p})}$ and $\mathrm{H}_{22}=0_{\mathrm{p} \times(\mathrm{s}-\mathrm{p})}$, the last two equations (31) result. Now, the proof of the Theorem 7 is complete.

\section{Algorithm 8. Design of the ROUIO.}

Step 1. Given system (1), verify the five related assumptions A4-A8.

Step 2. The matrix F of from (29) is chosen; the matrices $\mathrm{A}_{0}, \mathrm{~A}_{1}, \mathrm{C}, \mathrm{D}, \overline{\mathrm{N}}, \mathrm{H}, \overline{\mathrm{L}}, \overline{\mathrm{J}}, \overline{\mathrm{E}}$, and $\mathrm{Z}$ are partitioned with (29) and (30). The matrices $Z_{12}$ and $Z_{22}$ and thus the matrix $Z_{2}$ are arbitrarily chosen; the matrices $\mathrm{Z}_{1}, \overline{\mathrm{G}}_{\mathrm{i}} \forall \mathrm{i}=1 \cdots \mathrm{k}$, are obtained via (31).

Step 3. The matrices $\overline{\mathrm{N}}_{12}, \overline{\mathrm{N}}_{22}$ and thus the matrix $\overline{\mathrm{N}}_{2}$ are arbitrarily chosen; by solving system (35) with respect to the matrices $\overline{\mathrm{N}}_{11}, \overline{\mathrm{N}}_{21}, \overline{\mathrm{L}}_{1}, \overline{\mathrm{L}}_{2}$ or, directly, by means of (36), these four matrices are obtained; the matrices $\overline{\mathrm{N}}, \overline{\mathrm{J}}$ and $\overline{\mathrm{L}}$ are then calculated with (31). Matrices $\overline{\mathrm{E}}$ and $\mathrm{H}$ are computed by solving system (38).

Step 4. Using the above calculated matrix $\overline{\mathrm{N}}$, one checks if there exists a symmetric and positive-definite matrix $\overline{\mathrm{R}} \epsilon$ $\mathscr{R}^{\mathrm{n} \times \mathrm{n}}$ verifying the LMI (24); if so, the matrix $\overline{\mathrm{N}}$ has been properly obtained; otherwise, Steps 2-4 are repeated (in a "while" loop) until this condition is fulfilled.

Step 5. The observer described by (3) is completely designed and the time history of the system's estimated states can be obtained.

\section{Numerical Simulation Results}

5.1. The Quadruple-Tank Process. The quadruple-tank process is shown in Figure 1. It is composed of four connected tanks and two pumps that split water into two tanks [30, 31, 49]. The inlet flow of each tank is measured by an electromagnetic flow-meter and regulated by a pneumatic valve whereas the level of each tank $h_{i}(I=1 . .4)$ is measured by means of a pressure sensor. The process inputs are the input voltages of the pumps $\left(\vartheta_{1}\right.$ and $\left.\vartheta_{2}\right)$ and the output variables are the tank levels $\mathrm{y}_{1}$ and $\mathrm{y}_{2}$.

5.2. The Quadruple-Tank Process Model. For practical considerations, we assume that the operating regime of the process is well known that the quadruple-tank process is 
affected by delays and that the transport delays are perfectly symmetric. In such a case, the model of the process can be written as case study of model (1) and can be described by [30]

$$
\begin{aligned}
\dot{x}(t)= & A_{0} x(t)+A_{1} x\left(t-\tau_{1}\right)+B_{0} u\left(t-\tau_{2}\right) \\
& +B_{1} u\left(t-\tau_{3}\right)+\operatorname{Dd}(t), \\
y(t)= & C x(t),
\end{aligned}
$$

with $\mathrm{x}=\left[\begin{array}{llll}\mathrm{h}_{1} & \mathrm{~h}_{2} & \mathrm{~h}_{3} & \mathrm{~h}_{4}\end{array}\right]^{\mathrm{T}}$ being the state vector, $\mathrm{u}=$ $\left[\begin{array}{ll}\vartheta_{1} & \vartheta_{2}\end{array}\right]^{\mathrm{T}}$ being the input vector, and $\mathrm{y}=\left[\begin{array}{ll}\mathrm{y}_{1} & \mathrm{y}_{2}\end{array}\right]^{\mathrm{T}}$ being the output vector, respectively, and with

$$
\begin{aligned}
& \mathrm{A}_{0} \\
& =\left[\begin{array}{cccc}
-\frac{\mathrm{a}_{1}}{\mathrm{~A}_{1}} \sqrt{\frac{\mathrm{g}}{2 \mathrm{~h}_{10}}} & 0 & 0 & 0 \\
0 & -\frac{\mathrm{a}_{2}}{\mathrm{~A}_{2}} \sqrt{\frac{\mathrm{g}}{2 \mathrm{~h}_{20}}} & 0 & 0 \\
0 & 0 & -\frac{\mathrm{a}_{3}}{\mathrm{~A}_{3}} \sqrt{\frac{\mathrm{g}}{2 \mathrm{~h}_{30}}} & 0 \\
0 & 0 & 0 & -\frac{\mathrm{a}_{4}}{\mathrm{~A}_{4}} \sqrt{\frac{\mathrm{g}}{2 \mathrm{~h}_{40}}}
\end{array}\right], \\
& \mathrm{B}_{0}=\left[\begin{array}{cc}
\frac{\gamma_{1} \mathrm{k}_{1}}{\mathrm{~A}_{1}} & 0 \\
0 & \frac{\gamma_{2} \mathrm{k}_{2}}{\mathrm{~A}_{2}} \\
0 & 0 \\
0 & 0
\end{array}\right] \\
& \mathrm{A}_{1}=\left[\begin{array}{cccc}
0 & 0 & \frac{\mathrm{a}_{3}}{\mathrm{~A}_{1}} \sqrt{\frac{\mathrm{g}}{2 \mathrm{~h}_{30}}} & 0 \\
0 & 0 & 0 & \frac{\mathrm{a}_{4}}{\mathrm{~A}_{2}} \sqrt{\frac{\mathrm{g}}{2 \mathrm{~h}_{40}}} \\
0 & 0 & 0 & 0 \\
0 & 0 & 0 & 0
\end{array}\right] \text {, } \\
& \mathrm{B}_{1}=\left[\begin{array}{cc}
0 & 0 \\
0 & 0 \\
0 & \frac{\left(1-\gamma_{2}\right) \mathrm{k}_{2}}{\mathrm{~A}_{3}} \\
\frac{\left(1-\gamma_{1}\right) \mathrm{k}_{1}}{\mathrm{~A}_{4}} & 0
\end{array}\right]
\end{aligned}
$$

Using the following numerical values

$$
\begin{aligned}
\mathrm{D}_{1} & =\mathrm{D}_{2}=\mathrm{D}_{3}=\mathrm{D}_{4}=9.2 \mathrm{~cm}, \\
\mathrm{~A}_{1} & =\mathrm{A}_{2}=\mathrm{A}_{3}=\mathrm{A}_{4}=\pi\left(\frac{\mathrm{D}_{1}}{2}\right)^{2}, \\
\mathrm{~h}_{\max } & =50 \mathrm{~cm}, \\
\mathrm{~h}_{\mathrm{i} 0} & =\frac{\mathrm{h}_{\max }}{2}=25 \mathrm{~cm}, \\
\mathrm{~g} & =981 \mathrm{~cm} \cdot \mathrm{s}^{-2}, \\
\mathrm{~d}_{1} & =0.2 \mathrm{~cm},
\end{aligned}
$$

$$
\begin{aligned}
& \mathrm{a}_{1}=\mathrm{a}_{2}=\pi\left(\frac{\mathrm{d}_{1}}{2}\right), \\
& \mathrm{d}_{3}=0.9, \\
& \mathrm{a}_{3}=\mathrm{a}_{4}=\pi\left(\frac{\mathrm{d}_{3}}{2}\right)^{2}, \\
& \mathrm{k}_{1}=7.39, \\
& \mathrm{k}_{2}=6.92,
\end{aligned}
$$

the matrices from (1) are given by

$$
\begin{aligned}
& \mathrm{A}_{0}=\left[\begin{array}{cccc}
-0.0021 & 0 & 0 & 0 \\
0 & -0.0021 & 0 & 0 \\
0 & 0 & -0.0424 & 0 \\
0 & 0 & 0 & -0.0424
\end{array}\right] \text {, } \\
& \mathrm{B}_{0}=\left[\begin{array}{cc}
0.1113 \times \gamma_{1} & 0 \\
0 & 0.1042 \times \gamma_{2} \\
0 & 0 \\
0 & 0
\end{array}\right] \\
& A_{1}=\left[\begin{array}{cccc}
0 & 0 & 0.0424 & 0 \\
0 & 0 & 0 & 0.0424 \\
0 & 0 & 0 & 0 \\
0 & 0 & 0 & 0
\end{array}\right] \\
& \mathrm{B}_{1}=\left[\begin{array}{cc}
0 & 0 \\
0 & 0 \\
0 & \left(1-\gamma_{2}\right) \times 0.1042 \\
\left(1-\gamma_{1}\right) \times 0.1042 & 0
\end{array}\right] \text {. }
\end{aligned}
$$

5.3. Software Implementation of the Full-Order Observer. For simulation results, the following numerical values are chosen: $\mathrm{x}(0)=\left[\begin{array}{llll}-4 & 4 & 6 & -5\end{array}\right], \mathrm{d}(\mathrm{t})=0.3 \sin (2 \pi \mathrm{ft}), \mathrm{D}^{\mathrm{T}}=$ $\left[\begin{array}{cccc}10 & 20 & -12 & 15 \\ -23 & 28 & 30 & -36\end{array}\right], \gamma_{1}=0.333, \gamma_{2}=0.307, \alpha=0.4420$, and $\tau_{1}=5 \mathrm{~s}, \tau_{2}=3 \mathrm{~s}, \tau_{3}=4 \mathrm{~s}$. The control gain matrix is computed using the approach proposed in [1]

$$
K=\left[\begin{array}{rrrr}
-0.1603 & -0.1765 & -0.0795 & -0.2073 \\
-0.1977 & -0.1579 & -0.2288 & -0.0772
\end{array}\right]
$$

For the FOUIO software implementation, one obtains

$$
\mathrm{E}=\left[\begin{array}{cc}
-1 & 0 \\
0 & -1 \\
1.264 & -0.032 \\
-1.54 & 0.02
\end{array}\right]
$$




$$
\begin{aligned}
& \mathrm{P}=\left[\begin{array}{cccc}
0 & 0 & 0 & 0 \\
0 & 0 & 0 & 0 \\
1.26 & -0.032 & 1 & 0 \\
-1.54 & -0.020 & 0 & 1
\end{array}\right] \\
& \mathrm{G}_{0}=\left[\begin{array}{cc}
0 & 0 \\
0 & 0 \\
0.046 & -0.01 \\
-0.057 & 0.06
\end{array}\right] \\
& \mathrm{G}_{1}=\left[\begin{array}{cc}
0 & 0 \\
0 & 0 \\
0 & 0.072 \\
0.074 & 0
\end{array}\right] \\
& \mathrm{N}=\left[\begin{array}{cccc}
-1 & 0 & 0 & 0 \\
0 & -1 & 0 & 0 \\
1 & 1 & -0.0424 & 0 \\
1 & 1 & 0 & -0.0424
\end{array}\right] \\
& \mathrm{L}=\left[\begin{array}{cc}
0 & 0 \\
0 & 0 \\
-0.05 & -0.013 \\
-0.06 & 0.08
\end{array}\right] \\
& J=\left[\begin{array}{cc}
0 & 0 \\
0 & 0 \\
-0.043 & 0.095 \\
-0.025 & 0.017
\end{array}\right]
\end{aligned}
$$

5.4. Software Implementation of the Reduced-Order Observer. During the first step of the Algorithm 8, we find the matrices and vectors from (3). In this paper, the order is chosen as equal $\mathrm{n}=4, \mathrm{~m}=2, \mathrm{p}=2, \mathrm{q}=2$, and $\mathrm{s}=3$ and the constant time delays are chosen as $\tau_{1}=5 \mathrm{~s}, \tau_{2}=2 \mathrm{~s}$, and $\tau_{3}=4 \mathrm{~s}$. We obtain

$$
\begin{aligned}
& \overline{\mathrm{E}}=\left[\begin{array}{ll}
1 & 0 \\
0 & 1 \\
0 & 0 \\
0 & 0
\end{array}\right], \\
& \mathrm{H}=\left[\begin{array}{lll}
0 & 0 & 0 \\
0 & 0 & 0 \\
1 & 0 & 0 \\
0 & 1 & 0
\end{array}\right],
\end{aligned}
$$

$$
\begin{aligned}
& \overline{\mathrm{G}}_{0}=\left[\begin{array}{cc}
0 & 0 \\
0.1 & 0 \\
0 & 0.07
\end{array}\right] \text {, } \\
& \overline{\mathrm{G}}_{1}=\left[\begin{array}{cc}
0 & 0.072 \\
0.074 & 0 \\
0 & 0
\end{array}\right] \text {, } \\
& \overline{\mathrm{N}}=10^{13}\left[\begin{array}{ccc}
0 & 0 & 2.945 \\
0 & 0 & 0.46 \\
0 & 0 & 0
\end{array}\right] \\
& \overline{\mathrm{L}}=\left[\begin{array}{cc}
0 & 0 \\
0 & 0 \\
-0.05 & -0.013 \\
-0.06 & 0.08
\end{array}\right] \text {, } \\
& \bar{J}=\left[\begin{array}{cc}
0 & 0 \\
0 & 0 \\
-0.043 & 0.095 \\
-0.025 & 0.017
\end{array}\right] \text {, } \\
& Z=10^{-14}\left[\begin{array}{ccc}
0.2220 & -0.0439 & 0.5255 \\
0.1377 & 0.0111 & 0.8992 \\
0 & 0 & 0.9452
\end{array}\right]
\end{aligned}
$$

Figure 2 shows the effectiveness of two designed observers for the quadruple-process and their performances for which the variables $\mathrm{x}_{1}$ and $\mathrm{x}_{2}$ (variation of water levels in tanks 1 and 2) are measured and only the variables $x_{3}$ and $x_{4}$ (variation of water levels in tanks 3 and 4 ) are estimated. The effectiveness of two observers is proved by the superpose of the three curves.

\section{Conclusion}

This study considers the design of two approaches of UIOs for systems with multiple time-delays: a full-order delaydependent UIO and a reduced-order delay-dependent UIO. The quadruple-tank process was used as a benchmark to prove the effectiveness of the new observer algorithms for the case study of multivariable nonminimum phase systems with multiple delays.

\section{Data Availability}

The data used to support the findings of this study are included within the article.

\section{Conflicts of Interest}

The authors declare that there are no conflicts of interest regarding the publication of this paper. 

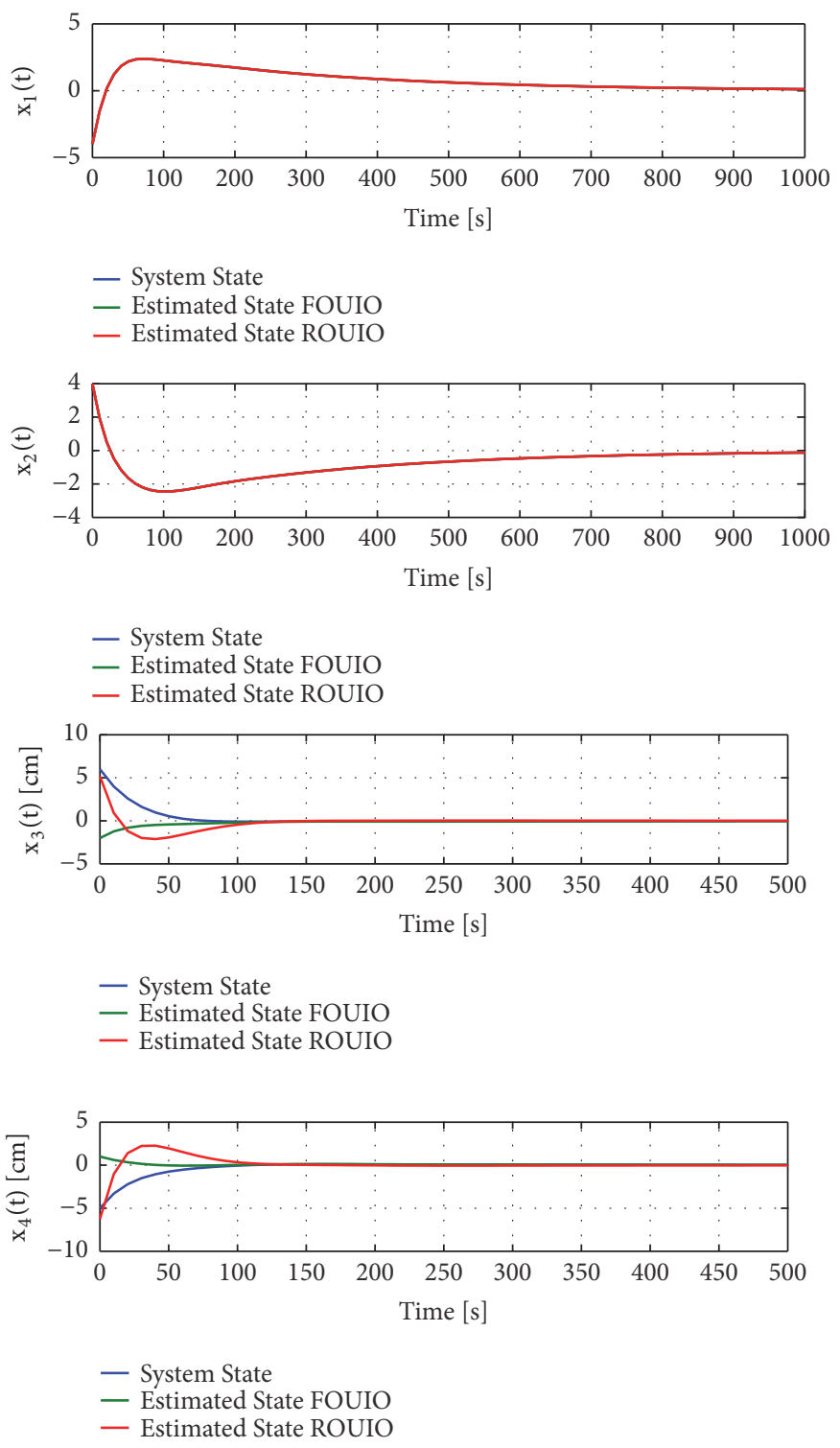

Figure 2: FOUIO and ROUIO of the quadruple-tank process.

\section{References}

[1] F. El Haoussi, E. H. Tissir, F. Tadeo, and A. Hmamed, "Delaydependent stabilisation of systems with time-delayed state and control: application to a quadruple-tank process," International Journal of Systems Science, vol. 42, no. 1, pp. 41-49, 2011.

[2] M. Darouach, M. Zasadzinski, and S. J. Xu, "Full-order observers for linear systems with unknown inputs," Institute of Electrical and Electronics Engineers Transactions on Automatic Control, vol. 39, no. 3, pp. 606-609, 1994.

[3] F. Zhang, S. Zong, X. Wang, and X. Ren, "An Expert PI Controller with Dead Time Compensation of Monitor AGC in Hot Strip Mill," Mathematical Problems in Engineering, vol. 2016, Article ID 3041538, 8 pages, 2016.

[4] H. Li, X. Jing, and H. R. Karimi, "Output-feedback-based $\mathrm{H}_{\infty}$ control for vehicle suspension systems with control delay," IEEE Transactions on Industrial Electronics, vol. 61, no. 1, pp. 436-446, 2014.
[5] R. Sanz, P. Garcia, Q.-C. Zhong, and P. Albertos, "PredictorBased Control of a Class of Time-Delay Systems and Its Application to Quadrotors," IEEE Transactions on Industrial Electronics, vol. 64, no. 1, pp. 459-469, 2017.

[6] S. Bououden, M. Chadli, L. Zhang, and T. Yang, "Constrained model predictive control for time-varying delay systems: Application to an active car suspension," International Journal of Control, Automation, and Systems, vol. 14, no. 1, pp. 51-58, 2016.

[7] W. Cao, Z. Liu, Y. Chang, and A. Szumanowski, "Direct Yaw-Moment Control of All-Wheel-Independent-Drive Electric Vehicles with Network-Induced Delays through ParameterDependent Fuzzy SMC Approach," Mathematical Problems in Engineering, vol. 2017, Article ID 5170492, 15 pages, 2017.

[8] O. Boubaker, V. E. Balas, A. Benzaouia, M. Chaabane, M. S. Mahmoud, and Q. Zhu, "Time-Delay Systems: Modeling, Analysis, Estimation, Control, and Synchronization," Mathematical Problems in Engineering, vol. 2017, Article ID 1398904, 3 pages, 2017. 
[9] M. S. Mahmoud, "Recent Progress in Stability and Stabilization of Systems with Time-Delays," Mathematical Problems in Engineering, vol. 2017, Article ID 7354654, 25 pages, 2017.

[10] E. Fridman, Introduction to Time-delay Systems: Analysis and Control, Springer, Berlin, Germany, 2014.

[11] B. Zhou, Truncated predictor feedback for time-delay systems, Springer, Berlin, Germany, 2014.

[12] E. Witrant, E. Fridman, O. Sename, and L. Dugard, Recent Results on Time-Delay Systems, vol. 5, Springer International Publishing, 2016.

[13] X.-M. Zhang, Q.-L. Han, A. Seuret, and F. Gouaisbaut, "An improved reciprocally convex inequality and an augmented Lyapunov-Krasovskii functional for stability of linear systems with time-varying delay," Automatica, vol. 84, pp. 221-226, 2017.

[14] W. Qian, M. Yuan, L. Wang, X. Bu, and J. Yang, "Stabilization of systems with interval time-varying delay based on delay decomposing approach," ISA Transactions, vol. 70, 6 pages, 2017.

[15] X. Cai, N. Bekiaris-Liberis, and M. Krstic, "Input-to-state stability and inverse optimality of linear time-varying-delay predictor feedbacks," Institute of Electrical and Electronics Engineers Transactions on Automatic Control, vol. 63, no. 1, pp. 233240, 2018.

[16] Q. Liu and B. Zhou, "Extended observer based feedback control of linear systems with both state and input delays," Journal of The Franklin Institute, vol. 354, no. 18, pp. 8232-8255, 2017.

[17] W. Belhaj and O. Boubaker, "MIMO PI Controllers for LTI Systems with Multiple Time Delays Based on ILMIs and Sensitivity Functions," Mathematical Problems in Engineering, vol. 2017, Article ID 1241545, 25 pages, 2017.

[18] B. Zhou, Q. Liu, and F. Mazenc, "Stabilization of linear systems with both input and state delays by observer-predictors," Automatica, vol. 83, pp. 368-377, 2017.

[19] R. Dormido, H. Vargas, N. Duro et al., "Development of a webbased control laboratory for automation technicians: the threetank system," IEEE Transactions on Education, vol. 51, no. 1, pp. 35-44, 2008.

[20] S. Di Cairano, A. Bemporad, I. V. Kolmanovsky, and D. Hrovat, "Model predictive control of magnetically actuated mass spring dampers for automotive applications," International Journal of Control, vol. 80, no. 11, pp. 1701-1716, 2007.

[21] A. C. Luo and R. P. Han, "The dynamics of a bouncing ball with a sinusoidally vibrating table revisited," Nonlinear Dynamics, vol. 10, no. 1, pp. 1-18, 1996.

[22] M. Jankovic, D. Fontaine, and P. V. Kokotović, “TORA example: cascade- and passivity-based control designs," IEEE Transactions on Control Systems Technology, vol. 4, no. 3, pp. 292-297, 1996.

[23] B. M. Chen, T. H. Lee, and V. Venkataramanan, Hard disk drive servo systems, Springer, Berlin, Germany, 2002.

[24] N. F. Al-Muthairi and M. Zribi, "Sliding mode control of a magnetic levitation system," Mathematical Problems in Engineering, vol. 2004, no. 2, pp. 93-107, 2004.

[25] O. Boubaker and R. Iriarte, The Inverted Pendulum in Control Theory and Robotics: From theory to new innovations, Institution of Engineering and Technology, Stevenage, UK, 2017.

[26] I. Fantoni and R. Lozano, "Stabilization of the Furuta pendulum around its homoclinic orbit," International Journal of Control, vol. 75, no. 6, pp. 390-398, 2002.

[27] D. J. Block, K. J. Åström, and M. W. Spong, “The Reaction Wheel Pendulum," Synthesis Lectures on Controls and Mechatronics, vol. 1, no. 1, pp. 1-105, 2007.
[28] F. Andreev, D. Auckly, S. Gosavi, L. Kapitanski, A. Kelkar, and W. White, "Matching linear systems, and the ball and beam," Automatica, vol. 38, no. 12, pp. 2147-2152, 2002.

[29] F. Matsuno and Y. Sakawa, "Modeling and Quasi-Static Hybrid Position/Force Control of Constrained Planar Two-Link Flexible Manipulators," IEEE Transactions on Robotics and Automation, vol. 10, no. 3, pp. 287-297, 1994.

[30] K. H. Johansson, "The quadruple-tank process: a multivariable laboratory process with an adjustable zero," IEEE Transactions on Control Systems Technology, vol. 8, no. 3, pp. 456-465, 2000.

[31] K. H. Johansson, A. Horch, O. Wijk, and A. Hansson, "Teaching multivariable control using the quadruple-tank process," in Proceedings of the The 38th IEEE Conference on Decision and Control (CDC), pp. 807-812, 1999.

[32] K. H. Johansson and J. L. R. Nunes, "A multivariable laboratory process with an adjustable zero," in Proceedings of the American Control Conference (ACC '98), pp. 2045-2049, 1998.

[33] T. Roinila, M. Vilkko, and A. Jaatinen, "Corrected Mathematical Model of Quadruple Tank Process," IFAC Proceedings Volumes, vol. 41, no. 2, pp. 11678-11683, 2008.

[34] W. Belhaj and O. Boubaker, "On MIMO PID control of the quadruple-tank process via ILMIs approaches: minimum and non-minimum case studies," in Proceedings of the 10th IFAC Symposium on Dynamics and Control of Process Systems (DYCOPS '13), pp. 481-486, Mumbai, India, 2013.

[35] K. H. Johansson, "Interaction bounds in multivariable control systems," Automatica, vol. 38, no. 6, pp. 1045-1051, 2002.

[36] I. Alvarado, D. Limon, W. García-Gabín, T. Alamo, and E. Camacho, "An Educational Plant Based on the Quadruple-Tank Process," IFAC Proceedings Volumes, vol. 39, no. 6, pp. 82-87, 2006.

[37] S. H. Said and F. M. Sahli, "A set of observers design to a quadruple tank process," in Proceedings of the 2008 IEEE International Conference on Control Applications (CCA) part of the IEEE Multi-Conference on Systems and Control, pp. 954-959, San Antonio, TX, USA, 2008.

[38] H. Gouta, S. H. Saï, N. Barhoumi, and F. M'Sahli, “Generalized predictive control for a coupled four tank MIMO system using a continuous-discrete time observer," ISA Transactions ${ }^{\circledR}$, vol. 67, pp. 280-292, 2017.

[39] C. Huang, E. Canuto, and C. Novara, "The four-tank control problem: Comparison of two disturbance rejection control solutions," ISA Transactions ${ }^{\circledR}$, vol. 71, pp. 252-271, 2017.

[40] N. Xavier, B. Bandyopadhyay, and R. Schmid, "Robust nonovershooting tracking using continuous control for linear multivariable systems," IET Control Theory \& Applications, vol. 12, no. 7, pp. 1006-1011, 2018.

[41] H. Gouta, S. H. Said, and F. M'Sahli, "Observer-based Backstepping liquid level controller for a quadruple tank process," in Proceedings of the 16th International Conference on Sciences and Techniques of Automatic Control and Computer Engineering, STA 2015, pp. 351-356, Tunisia, 2015.

[42] F. Smida, S. H. Said, and F. M'Sahli, "Cascade unknown input observers applied to a quadruple tank process," in Proceedings of the 2015 12th International Multi-Conference on Systems, Signals \& Devices (SSD), pp. 1-6, Mahdia, Tunisia, 2015.

[43] I. Manaa, N. Barhoumi, and F. M'Sahli, "Unknown inputs observers design for a class of nonlinear switched systems," International Journal of Modelling, Identification and Control, vol. 23, no. 1, pp. 45-54, 2015. 
[44] M. Lungu and R. Lungu, "Full-order observer design for linear systems with unknown inputs," International Journal of Control, vol. 85, no. 10, pp. 1602-1615, 2012.

[45] S. Ben Warrad and O. Boubaker, "Robust observer for multiple time-delay systems with unknown inputs," in Proceedings of the 16th International Conference on Sciences and Techniques of Automatic Control and Computer Engineering, (STA '15), pp. 859-864, Tunisia, 2015.

[46] S. B. Warrad and O. Boubaker, "Full order unknown inputs observer for multiple time-delay systems," International Journal On Smart Sensing and Intelligent Systems, vol. 9, no. 4, pp. 17501775, 2016.

[47] S. Ben Warrad and O. Boubaker, "Design of unknown input observers for linear systems with state and input delays," in Proceedings of the 15th IEEE International Multi-Conference on Systems, Signals and Devices, Hammamet, Tunisia, 2018.

[48] S. Ben Warrad, O. Boubaker, M. Lungu, and Q. Zhu, "On unknown inputs observer design for linear systems with delays in states and inputs," in New Trends in Observer-based Control: An Introduction to Design Approaches and Engineering Applications, Elsevier Academic Press, 1st edition, 2019.

[49] W. Belhaj and O. Boubaker, "Multivariable PID Control via LMIs: Performances Assessment," International Journal on Smart Sensing \& Intelligent Systems, vol. 8, no. 4, pp. 1896-1916, 2015. 


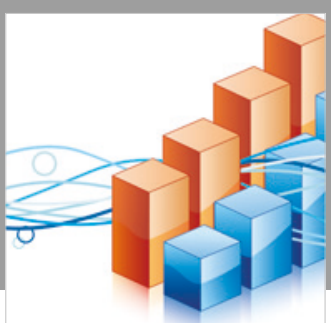

Advances in

Operations Research

\section{-n-m}
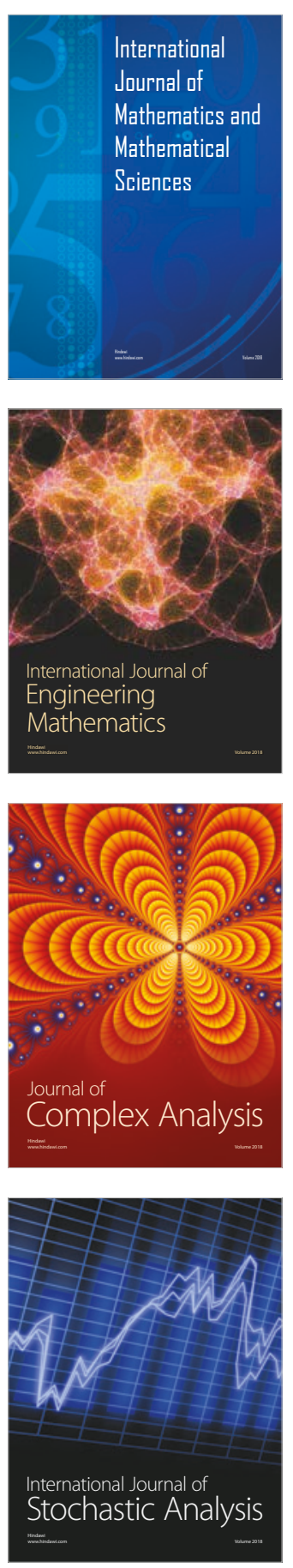
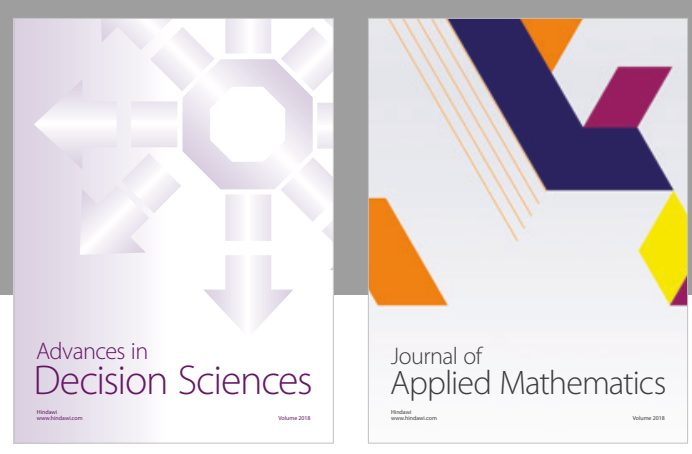

Journal of

Applied Mathematics
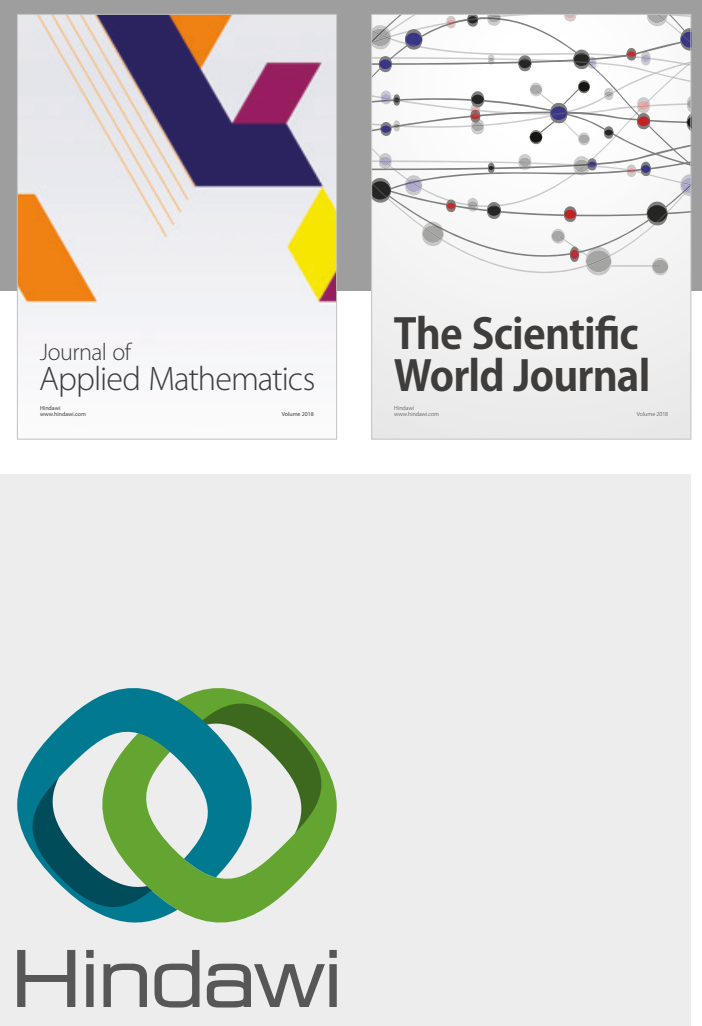

Submit your manuscripts at

www.hindawi.com

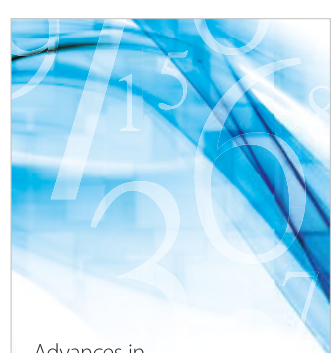

Advances in
Numerical Analysis
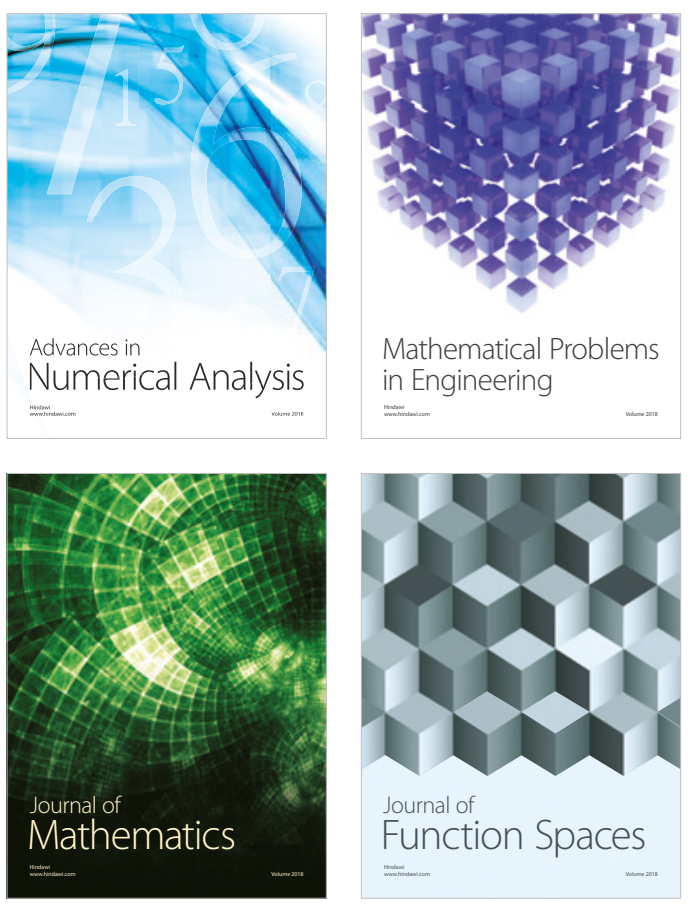

Mathematical Problems in Engineering

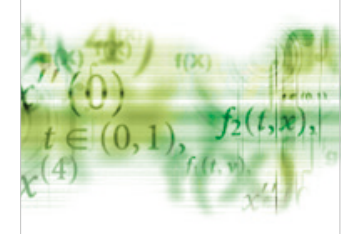

International Journal of

Differential Equations

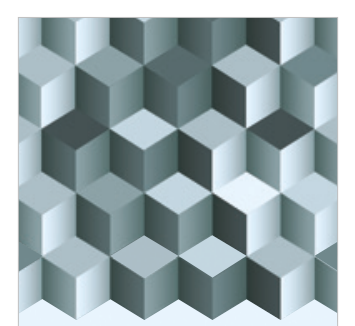

Journal of

Function Spaces

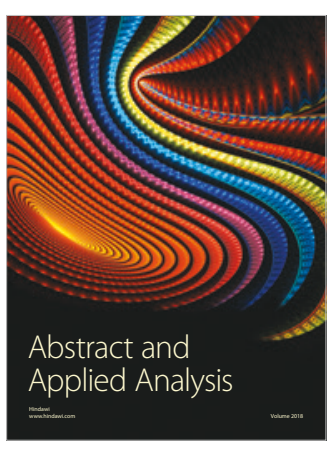

The Scientific

World Journal

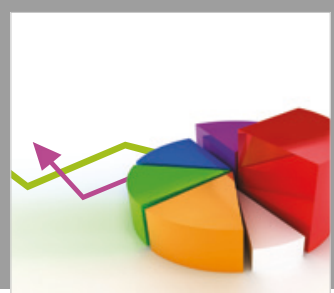

Journal of

Probability and Statistics
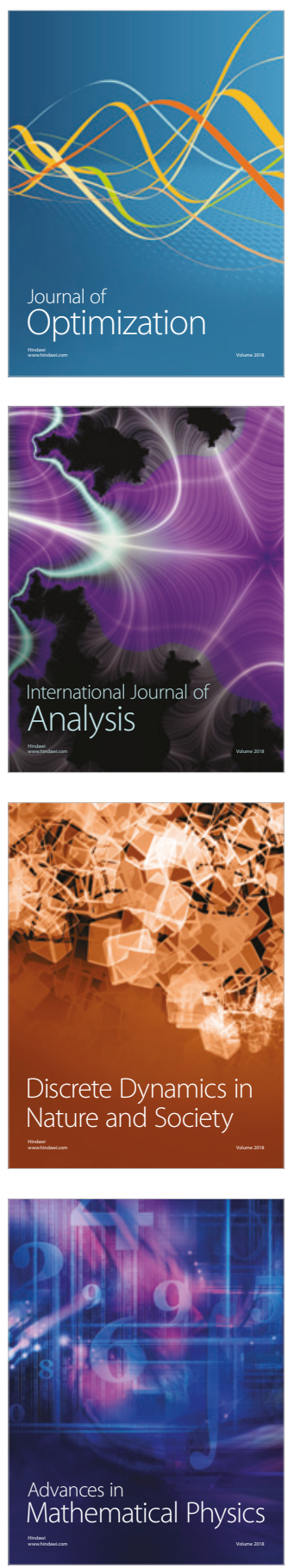